\title{
Investigating Machinability in Hard Turning of AISI 52100 Bearing Steel Through Performance Measurement: QR, ANN and GRA Study
}

\author{
A. Panda ${ }^{1}$, A. K. Sahoo ${ }^{1 *}$, I. Panigrahi ${ }^{1}$ and A. K. Rout $^{2}$ \\ ${ }^{1}$ School of Mechanical Engineering, Kalinga Institute of Industrial Technology (KIIT), \\ Deemed to be University, Bhubaneswar, \\ Odisha, 751024, India \\ *Email: aklala72@gmail.com \\ Tel: +91-0674-6540805 \\ ${ }^{2}$ Department of Production Engineering, VSSUT, Burla, Odisha, India
}

\begin{abstract}
The existing endeavor investigates on machinability characteristics through performance measurement of flank wear, surface quality and chip morphology during finish turning of AISI 52100 bearing steel ( $55 \pm 1 \mathrm{HRC}$ ) under dry environment employing carbide insert coated along with various layers $\left(\mathrm{TiN} / \mathrm{TiCN} / \mathrm{Al}_{2} \mathrm{O}_{3}\right)$. Secondly the influence of machining variables viz. cutting speed, feed rate and depth of cut on responses are assessed by ANOVA and modeled through quadratic regression and artificial neural network. Multiparametric optimization of cutting conditions has been obtained through Taguchi based grey relational analysis. Finally, tool life at ideal conditions has been evaluated through experiment. Based on the study, it is disclosed that coated carbide with multilayer insert outperformed during hard machining as wear at the flank surface and surface quality are within the benchmark cap of $0.3 \mathrm{~mm}$ and 1.6 microns respectively. From the chip morphology analysis, multilayer coated carbide insert generates lower temperature and maintains cutting edge sharpness and delays the growth of tool wear. ANN model using multilayered feed forward network yields accurate prediction of responses with minimum error percentage compared to QR model. The optimal parametric combination through GRA approach is found to be d1 $(0.1 \mathrm{~mm})-\mathrm{f} 1(0.04 \mathrm{~mm} / \mathrm{rev})-\mathrm{v} 2(110 \mathrm{~m} / \mathrm{min})$ and is greatly improved. Feed is the compelling aspect for multi-responses pursued by cutting speed. The tool life at optimized cutting condition is found to be approximately 19 minutes.
\end{abstract}

Keywords: Hard turning, Machinability, Grey relational analysis, Artificial neural network, Analysis of variance, Regression.

\section{NOMENCLATURE}

$\begin{array}{ll}\text { d } & \text { depth of cut }(\mathrm{mm}) \\ \mathrm{f} & \text { feed }(\mathrm{mm} / \mathrm{rev}) \\ \mathrm{V} & \text { cutting speed }(\mathrm{m} / \mathrm{min}) \\ \mathrm{VBc} & \text { flank wear at nose corner }(\mathrm{mm}) \\ \mathrm{R}_{\mathrm{a}} & \text { arithmetic surface roughness average }(\mu \mathrm{m}) \\ \mathrm{DF} & \text { degrees of freedom } \\ \mathrm{MS} & \text { mean square } \\ \mathrm{P} & \text { probability of significance } \\ \text { GRA } & \text { Grey relational analysis }\end{array}$




$\begin{array}{ll}\text { OA } & \text { orthogonal array } \\ \text { RSM } & \text { response surface methodology } \\ \text { ANN } & \text { artificial neural network } \\ \text { AISI } & \text { American Iron and Steel Institute } \\ \text { HRC } & \text { Rockwell hardness } \\ \text { CNC } & \text { computerized numerical control } \\ \text { CVD } & \text { chemical vapor deposition } \\ \text { r } & \text { nose radius (mm) } \\ \text { SS } & \text { sum of squares } \\ \text { F } & \text { variance ratio } \\ \text { ANOVA } & \text { analysis of variance } \\ \gamma & \text { back rake angle } \\ \text { CBN } & \text { cubic boron nitride } \\ \text { QR } & \text { quadratic regression } \\ \text { R }^{2} & \text { coefficient of determination }\end{array}$

\section{INTRODUCTION}

Grinding is adopted as the traditional machining process of finishing hardened workpiece over many years. It has certain benefits and limitations like less material removal rate as well as time consuming and costly operations. Now-a-days, hard turning (single point cutting process) is emerging an evolving technology that has significant benefit over cylindrical grinding such as higher productivity, lesser utilization of power consumption, higher process flexibility producing complex geometry, less cost, time, and superior surface integrity, ecological and environmentally friendly due to machining under dry environment. Due to this, manufacturing costs could be decreased to 30 times if this newer technology could be applied to manufacture parts [1]. Thus now-a-days it is successively replacing grinding in most cases because it eliminates rough grinding, fine grinding and honing operations. Thus, the above cited advantages of hard machining can only be obtained with appropriate selection of process parameters, cutting tool materials and geometry and cutting environment. Several works have been reported for the use of different cutting tool materials in hard machining for the improvement of processes such as obtaining better surface quality with lower tool wear rate and higher productivity. The imperative independent variables like cutting speed (v), feed (f), and depth of cut (d) decides many predictable machinability aspects namely surface roughness, wear at the tool surface and tool life, temperature at the cutting zone, cutting forces and amount of material removed in hard machining. Diverse manufacturing giants like automotive manufacturer, bearings die and mold and aerospace desire output having accomplished surface character without compromising the productivity. So, in order to understand better hard turning process, a comprehensive literature review is conducted and presented.

Ozel et al. [2] examined average surface quality and wear at the flank surface of the tool in turning of hardened AISI D2 grade steel (60 HRC) employing ceramic wiper cutting tool. Multiple regression and neural network models have been developed for predicting the responses. A good range of surface quality below 0.2 microns are achieved through wiper inserts and flank wear value reaches $0.15 \mathrm{~mm}$ at 15 minutes of machining time at higher speeds. Neural network model is obtained to be suitable in the studied ranges of cutting conditions. Gaitonde et al. [3] perceived that wiper ceramic tool execute exceptionally contrast to conventional insert during machining D2 cold work tool steel in 
context to surface quality and wear at the tool surface. However traditional ceramic insert diminishes the turning power and force. Das et al. [4] investigated wear at the flank surface, surface quality and chip morphology in finish machining of AISI 4140 hardened steel working with ceramic insert coated with TiN through statistical techniques. The mathematical models have been developed and optimized the process parameters. Feed is found to be the deciding factor for surface quality pursued by cutting speed. Cutting speed and interaction impact of feed depth of cut have the significance on wear of the flank surface. Serrated saw tooth chips are formed at higher feed thus reducing the surface finish. Mohamed Yallese et al. [5] analyzed the behavior of CBN tools in machining of $100 \mathrm{Cr} 6$ (60 HRC) bearing steel and observed to be higher wear resistance.

Cutting speed about $120 \mathrm{~m} / \mathrm{min}$ is the ideal parameter yielding acceptable limit of flank wear below $0.4 \mathrm{~mm}$. At higher cutting speed $(280 \mathrm{~m} / \mathrm{min})$, instability of the machining system occurs. The investigation revealed that turning of hardened material successfully replaces the traditional grinding process as far as surface roughness is concerned. Tamizharasan et al. [6] studied the hard turning of crank pin material by polycrystalline cubic boron nitride tool with respect to part quality, tool life and tool wear, material removal and economics. It is observed that A-grade CBN inserts suitable compared to alternative category in turning of hardened material as it gives superior surface quality along curtailed tool wear. Zhang et al. [7] examined turning of heat treated rolling bearing steel (62-63 HRC) using CBN cutting tool through Taguchi orthogonal array. Better surface integrity has been achieved during machining through appropriate parametric conditions in name of surface quality, thermal damage layer and residual stresses. Sahin [8] examined the potential of CBN and ceramic tool regarding tool life during hard turning AISI 52100 bearing steel (659 HV) adopting Taguchi approach and ANOVA method. The results indicated that the cutting speed is the utmost convincing aspect on the cutting life of tool pursued by insert hardness and next is feed. CBN cutting tool outperformed over ceramic inserts during machining. Regression model of First and second order exponential models were generated to ascertain the correlations. Bouacha et al. [9] examined the dry turning of 64 HRC AISI 52100 steel bar employing CBN insert through statistical analysis applying RSM in context to surface quality and cutting forces.

The optimum parameter has been obtained through composite desirability approach with RSM. Feed and speed has the greater brunt on surface roughness. Depth of cut has the highest impact on cutting forces. Guddat et al. [10] explored the surface integrity and cutting forces in machining of heat treated AISI 52100 steel having hardness values ranging from 58-62 HRC using $\mathrm{CBN}$ wiper geometry insert. PCBN wiper inserts yields better surface roughness and elevated compressive residual stresses correlate to conventional cutting tool in machining. Mahfoudi et al. [11] studied turning of AISI 4140/ $42 \mathrm{CrMo} 4$ grade steel (50 HRC) with PCBN insert at higher cutting speeds (300 and 400 $\mathrm{m} / \mathrm{min}$ ). Better surface finish with significant tool life is calculated which shows its application in industrial applications. Bensouilah et al. [12] worked on the impact of machining factors on surface quality and cutting force while turning of AISI D3 hardened steel using mixed ceramic cutting tools through Taguchi approach. Coated CC6050 ceramic insert induced better surface quality i.e. 1.6 times better than uncoated CC650 ceramic tool whereas uncoated ceramic tool was helpful for decreasing the machining force. Aouici et al. [13] examined the influence of cutting speed, feed and work material hardness along with depth of cut on surface quality along with cutting force in turning of hardened AISI H11 grade steel using CBN cutting tools through RSM approach and developed mathematical models. 
Components of cutting force are mostly swayed by depth of cut and work material hardness. Work material hardness and feed are the dominating parameter in case of average surface finish. Hosseini et al. [14] studied the formation of white layer in turning AISI 52100 hardened steel using CBN insert. Thermally developed white layers include higher amounts of retained austenite in contrast to unaffected material and show elevated tensile residual stresses. Formation of white layer exclusively owing to extreme plastic deformation and no retained austenite could be studied. Moreover, the surface and subsurface residual stresses were found to be compressive in nature. Oliveira et al. [15] presented an experiment on radial turning of workpiece material AISI 4340 hardened steel with continuous and interrupted surfaces employing PCBN and ceramic inserts. Higher tool life obtained with PCBN insert and similar result was occurred in interrupted turning process for both inserts. PCBN tools observed to superior for surface roughness in continuous and interrupted surfaces.

Kurt and Seker [16] studied the turning hardened AISI 52100 steel using PCBN insert and explored the influence of chamfer angle on the tool stresses, cutting forces, principal and von Mises stress. Chamfer angle conceive a greater impact on the cutting forces and insert stresses and critical chamfer angle of 20 degree is recommended in finish hard turning. Dosbaeva et al. [17] compared the performance of coated carbide and PCBN inserts in finish hard turning of D2 steel (52 HRC). Experimental outcome concluded that the coated carbide insert can perform well than PCBN in turning the chosen workmaterial within a conceived span of cutting speeds along with temperature domain. Paiva et al. [18] studied turning of heat treated AISI 52100 grade steel employing wiper mixed ceramic insert coated with TiN over multi array robust criterion design. With the use of wiper inserts, twice feed rate can be used compared to traditional insert geometry to achieve surface quality approximately half value i.e. $\mathrm{Ra}=0.228$. Next to, maximum yield attained with wiper insert are superior to the value achieved along with traditional ones with lower surface roughness values. Raghavan et al. [19] observed the possible advantages of laser tempering stationed turning operation over the traditional turning mechanism of heat treated AISI 52100 graded steel. Sahoo and Sahoo [20] investigated dry turning tests of AISI 4340 hardened steel having 47 HRC employing coated carbide tool concerning its machinability analysis. The investigation reveals the possibility of carbide insert coated with several layers in finish turning of hardened material even at higher cutting speeds. Zuperl and Cus [21] suggested a neural network technique for multiple objective optimization of machining variables which ensures simple, fast and efficient selection of optimum cutting parameters.

Chinchanikar and Choudhury [22] evaluated the characteristic of coated carbide insert in machining of AISI 4340 hardened steel at different hardness. Considering reduced feed, decreased depth of cut and by controlling the cutting speed to 235 and 144 $\mathrm{m} / \mathrm{min}$; at during same turning of 35 and $45 \mathrm{HRC}$ work piece achieves minimal cutting forces, surface quality and superior tool life. Sahu et al. [23] observed that spray impingement cooling function in turning of hardened AISI 1015 steel boost the achievement correlate to cutting in dry conditions. Davim et al. [24] developed ANN model applying error backpropagation training algorithm for prediction of surface roughness during turning free machining steel. An immensely non-linear relation among surface quality variables and the cutting conditions exists which defends development of ANN model. Najiha et al. [25] studied optimization in end milling operation with minimum quantity lubrication for flank wear. Genetic algorithm was used for optimization and the best Pareto design was obtained using multi-criteria decision making. 
Referring to literatures, it is observed that $\mathrm{CBN}$ and ceramic cutting inserts are widely applied in manufacturing industries particularly in machining hardened steel because of their higher hardness, wear resistant, high hot hardness, chemical balance and low fracture toughness characteristics and proved to be effective as reported. Therefore, substitution of costly CBN and ceramic inserts in hard machining needs to be searched and detailed investigations with economical alternative carbide inserts will definitely open an avenue for further reduction of manufacturing cost during machining without compromising with quality of the product. Further, the promising material like AISI 52100 is widely used in the manufacturing industries as bearing steel in large scale and machining of the material at hardened state is usually performed with the help of CBN and ceramic inserts. Again, turning of hardened AISI 52100 grade steel at elevated hardness above $50 \mathrm{HRC}$ using coated carbide tool is scarcely examined and lacking as far as literature studies are concerned. Thus, more investigations on conduct of coated carbide insert in turning of heat treated AISI 52100 grade steel is categorical worthy and beneficial for machining industries point of view to achieve their goals. This is the novelty of the present research which has been extensively investigated in the present paper.

Thus, the present research is focused on investigating some machinability study in turning AISI 52100 hardened steel $(55 \pm 1 \mathrm{HRC})$ with coated carbide multilayer inserts with respect to surface roughness, flank wear, chip morphology and tool life and explored the significance of machining variables viz. cutting speed, feed and depth of cut on machinability. The mathematical models are developed for responses through quadratic regression $(\mathrm{QR})$ and artificial neural network (ANN) approach and multi-response optimization of cutting conditions has been obtained through Taguchi based grey method. ANOVA studies are conducted to find the significant machining parameters on responses. Finally, at optimized parametric conditions the tool life have been performed and recommended.

\section{MATERIALS AND METHOD}

AISI 52100 is a high carbon, chrome based low alloy steel that is especially used in the production of anti-friction bearings i.e. precision ball bearings and roller bearings. It is popularly known as bearing steel because of superior hardness at room temperature and can operate continuously up to $120^{\circ} \mathrm{C}$. An advantage of chrome bearing steel is of cost effective and long working life. AISI 52100 steel is widely used in engineering applications which includes manufacture of aircraft bearings, CV joints, ball screws, gauges, knife etc. The workpiece was heated to austenizing temperature of $930{ }^{\circ} \mathrm{C}$, holding it for 30 minutes and quenched in oil. To get the homogeneous structure and eliminate residual stresses on the workpiece, material was reheated to $250{ }^{\circ} \mathrm{C}$ for 30 minutes followed by air cooling. The heat-treated samples were measured for hardness and found to be $55 \pm 1$ HRC. With the help of Spectro metal analyzer (Spectro Max), the chemical composition test for the workpiece was performed and found to be in percentage by weight shown in Table 1 .

Table 1. Chemical composition of AISI 52100 steel specimen.

\begin{tabular}{cccccccccc}
\hline Element & $\mathrm{C}$ & $\mathrm{Si}$ & $\mathrm{Mn}$ & $\mathrm{P}$ & $\mathrm{S}$ & $\mathrm{Cr}$ & $\mathrm{Ni}$ & $\mathrm{Cu}$ & $\mathrm{Fe}$ \\
\hline wt.\% & 0.940 & 0.277 & 0.491 & 0.046 & 0.022 & 1.210 & 0.076 & 0.058 & Balance \\
\hline
\end{tabular}




\section{Machine Tool}

The turning tests on hardened AISI 52100 steel were carried out on a computerized numerical control (CNC) turning centre (Jobber XL) of maximum $3500 \mathrm{rpm}$ spindle speed and $16 \mathrm{~kW}$ spindle power with Sinumeric controller under varying parametric ranges. The tests are conducted under dry environment. The workpiece of $120 \mathrm{~mm}$ length and $40 \mathrm{~mm}$ diameter was used in experimentation within 1:4 diameters to length ratio so as to maintain stability of the machining systems. Also, tailstock support was provided by drilling a centre hole on the face of the workpiece. The heat-treated surfaces were cleaned by conducting some preliminary turning operation before actual machining. The operating length was definite as $100 \mathrm{~mm}$ for all the experimental runs.

\section{Cutting Insert}

Turning tests are performed using MTCVD (moderate temperature chemical vapour deposition) carbide insert coated with several layer (TiN/TiCN/Al ${ }_{2} \mathrm{O}_{3}$ ) of ISO geometry CNMG $120408\left(80^{\circ}\right.$ diamond shape) type of nose radius $0.8 \mathrm{~mm}$. The three layers of coatings on cemented carbide substrate are of TiN base layer, TiCN middle layer and $\mathrm{Al}_{2} \mathrm{O}_{3}$ top layer designated as $\mathrm{HK} 150$ grade (WIDIA make) of K-type application range. The tool was solidly attached on right hand type PCLNR2525 M12 tool holder with included angle of $80^{\circ}$, back rake of $-6^{\circ}$, clearance angle of $5^{\circ}$ and approach angle of $95^{\circ}$ respectively. Cutting tool height, overhang length and tool geometry was remaining constant throughout the experiments. Micro hardness of inserts were measured with Vickers micro hardness tester applying a $1 \mathrm{~kg}$ load and found to be $1656 \mathrm{HV}$. The geometry of cutting insert and coating layer is shown in Figure 1 (a) and (b).

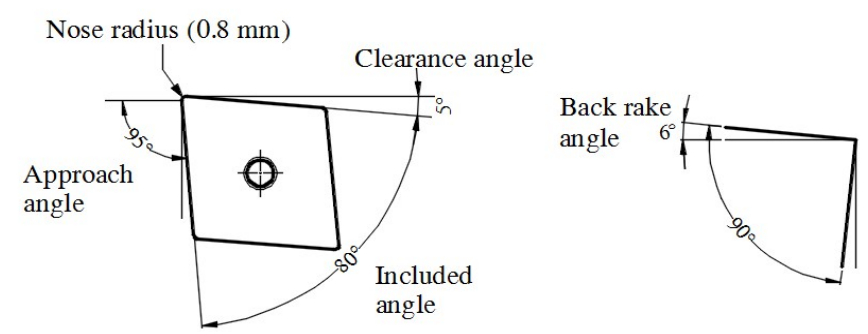

(a)

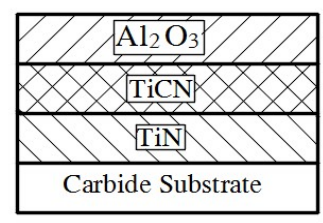

(b)

Figure 1. (a) Geometry of cutting inserts (b) coating layer and carbide substrate.

\section{Cutting Parameters}

The dry hard turning tests were experimented by means of Taguchi $\mathrm{L}_{16}$ orthogonal array (OA) design which comprises of total 16 experimental runs of different combinations of process inputs such as cutting speed (v), feed (f) and depth of cut (d) respectively each at four levels $[26,27,28,29]$. The levels of depth of cut vary from $0.1,0.2,0.3$ and $0.4 \mathrm{~mm}$ respectively. Feed rate varies from $0.04,0.08,0.12$ and $0.16 \mathrm{~mm} / \mathrm{rev}$ respectively. Similarly, cutting speed varies from 70, 110, 150 and $190 \mathrm{~m} / \mathrm{min}$ respectively. A new cutting edge was used for each experimental run. The effects of various parameters were analyzed after completion of all experiments. 


\section{Measurement of Flank Wear, Surface Roughness and Chip Morphology}

The machined workpiece and cutting inserts are cleaned before any measurement. Wear on the flank surface and its advancement was measured after each experiment with the help of Nikon profile projector having magnification range of 20x to 50x (model V10AD). The visualization of flank wear was visualized by stereo zoom microscope (RSM8, Radical instrument), India attached with camera along with PC arc soft web cam software. The flank wear criteria (VBc) was taken as $0.3 \mathrm{~mm}$ as per ISO 3685 standard and was determined at nose corner portion. The roughness average ( $\mathrm{Ra}$ ) was measured thrice for the machined sample at three locations through surface roughness tester (Taylor Hobson, Surtronic 25) having cutoff and assessment length was fixed at 0.8 and $4 \mathrm{~mm}$ respectively as per ISO 4287 standard and average value was recorded for investigation. The permissible surface roughness limit was fixed as 1.6 microns so as to be comparable with cylindrical grinding. During machining experiment, chips were collected to investigate its morphology i.e. shapes and colors through digital camera. The experimental arrangement is shown in Figure 2.

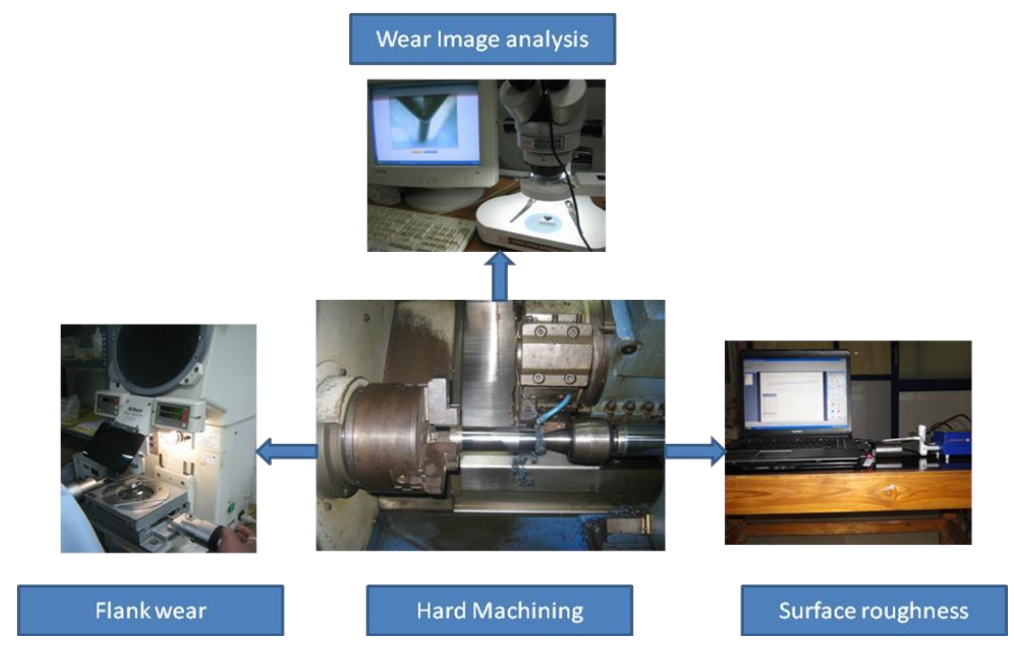

Figure 2. Experimental setup.

\section{RESULTS AND DISCUSSION}

\section{Analysis of Flank Wear}

The hard-turning tests are carried out to investigate different types of tool wear under varying parametric range from the captured images. The experimental outcomes and images of wear at the flank surface and chips are shown in Figure 3 and 4, and Table 2 respectively. At depth of cut of $0.1 \mathrm{~mm}$ (run 1, 2, 3 and 4), flank wear rises with rise of cutting speed from 70-150 $\mathrm{m} / \mathrm{min}$ and feed up to $0.04-0.12 \mathrm{~mm} / \mathrm{rev}$ but at lower rate. The flank wear evolution ranges from 0.06 to $0.098 \mathrm{~mm}$ respectively. However it increases at slightly higher rate at higher cutting speed and feed of $190 \mathrm{~m} / \mathrm{min}$ and $0.16 \mathrm{~mm} / \mathrm{rev}$ respectively and reaches $0.155 \mathrm{~mm}$ (at run 4) but still within the limiting range of tool wear of $0.3 \mathrm{~mm}[20,29,30,31]$.The cutting inserts are free from any types of failures such as chipping, fracturing, and adhesion and induced regular flank wear with stable machining. Similar observations are noticed at depth of cut of $0.2 \mathrm{~mm}$ (Run 5, 6, 7, 8), $0.3 \mathrm{~mm}$ (Run 9, 10, 11 and 12) and 0.4mm (Run 13, 14, 15 and 16) respectively. Especially 
at enhanced cutting speed $(190 \mathrm{~m} / \mathrm{min})$ of Run 7 and 10, accelerated tool wear along with minor chipping is observed from the captured images of the cutting edges and it may be due to the higher thermo-mechanical loadings on the cutting edges. Also, at higher cutting speed, cutting temperature increases at flank portion due to faster rubbing between tool and workpiece through less contact time which softens the workpiece and accelerates the wear. However, flank wear values are within the criteria cap of $0.3 \mathrm{~mm}$ and interestingly it is below $0.2 \mathrm{~mm}$ also i.e. $0.194 \mathrm{~mm}$ at run 7 and $0.178 \mathrm{~mm}$ at run 10 respectively.

In general, tool wear is characterized by abrasion and diffusion. Abrasion is due to friction generated at the interfaces accompanied by immense mechanical loading on the cutting edge while machining. At higher cutting speeds, interface temperature rises quickly that leads to softening of the cutting inserts because of generation of heat. The combination of these two mechanisms such as abrasion and diffusion accelerate surface chipping and degrades the cutting edge of the insert. However, in the inspected range, no major chipping is occurred while machining hardened AISI 52100 steel. Thus, turning of AISI 52100 hardened steel with coating layer of carbide insert ( $\mathrm{TiN} / \mathrm{TiCN} / \mathrm{Al}_{2} \mathrm{O}_{3}$ ) is characterized by stable and steady turning without any untimely failure like plastic deformation, chipping and/or catastrophic failure on the cutting tip.

Table 2. Experimental results.

\begin{tabular}{|c|c|c|c|c|c|c|c|}
\hline \multirow{2}{*}{$\begin{array}{l}\text { Run } \\
\text { No }\end{array}$} & \multicolumn{3}{|c|}{ Cutting parameters } & \multicolumn{2}{|c|}{ Experimental results } & \multicolumn{2}{|c|}{ Chip morphology } \\
\hline & $\begin{array}{c}\mathrm{d} \\
(\mathrm{mm})\end{array}$ & $\begin{array}{c}\mathrm{f} \\
(\mathrm{mm} / \mathrm{rev})\end{array}$ & $\begin{array}{c}\mathrm{v} \\
(\mathrm{m} / \mathrm{min})\end{array}$ & $\begin{array}{l}\text { VBc } \\
(\mathrm{mm})\end{array}$ & $\begin{array}{c}\mathrm{Ra} \\
(\mu \mathrm{m})\end{array}$ & Shape & Colour \\
\hline 1 & 0.1 & 0.04 & 70 & 0.060 & 1.09 & Ribbon & Grey \\
\hline 2 & 0.1 & 0.08 & 110 & 0.070 & 0.34 & helical & Grey \\
\hline 3 & 0.1 & 0.12 & 150 & 0.098 & 0.51 & $\begin{array}{c}\text { Helical } \\
\text { (Saw) }\end{array}$ & Grey \\
\hline 4 & 0.1 & 0.16 & 190 & 0.155 & 1.15 & $\begin{array}{c}\text { Helical } \\
\text { (saw) }\end{array}$ & Grey \\
\hline 5 & 0.2 & 0.04 & 110 & 0.082 & 0.30 & Helical & Grey \\
\hline 6 & 0.2 & 0.08 & 70 & 0.068 & 0.52 & Ribbon & Grey \\
\hline 7 & 0.2 & 0.12 & 190 & 0.194 & 1.01 & Helical & Blue \\
\hline 8 & 0.2 & 0.16 & 150 & 0.121 & 1.33 & Helical & Grey \\
\hline 9 & 0.3 & 0.04 & 150 & 0.090 & 0.20 & $\begin{array}{c}\text { Ribbon } \\
\text { (Saw) }\end{array}$ & Grey \\
\hline 10 & 0.3 & 0.08 & 190 & 0.178 & 0.78 & $\begin{array}{c}\text { Ribbon } \\
\text { (saw) }\end{array}$ & Grey \\
\hline 11 & 0.3 & 0.12 & 70 & 0.080 & 0.56 & Helical & Grey \\
\hline 12 & 0.3 & 0.16 & 110 & 0.115 & 1.20 & Helical & Blue \\
\hline 13 & 0.4 & 0.04 & 190 & 0.145 & 0.40 & $\begin{array}{c}\text { Helical } \\
\text { (saw) }\end{array}$ & Blue \\
\hline 14 & 0.4 & 0.08 & 150 & 0.122 & 0.46 & $\begin{array}{c}\text { Helical } \\
\text { (saw) }\end{array}$ & Grey \\
\hline 15 & 0.4 & 0.12 & 110 & 0.113 & 0.49 & Ribbon & Blue \\
\hline 16 & 0.4 & 0.16 & 70 & 0.100 & 1.20 & Ribbon & Grey \\
\hline
\end{tabular}




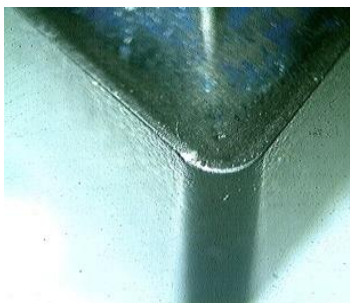

Run-1

$(\mathrm{d}=0.1 \mathrm{~mm}$,

$\mathrm{f}=0.04 \mathrm{~mm} / \mathrm{rev}$,

$\mathrm{v}=70 \mathrm{~m} / \mathrm{min}$ )

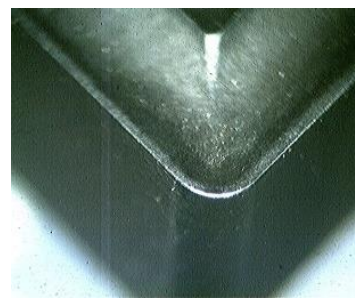

Run-9

$(\mathrm{d}=0.3 \mathrm{~mm}$,

$\mathrm{f}=0.04 \mathrm{~mm} / \mathrm{rev}$,

$\mathrm{v}=150 \mathrm{~m} / \mathrm{min}$ )

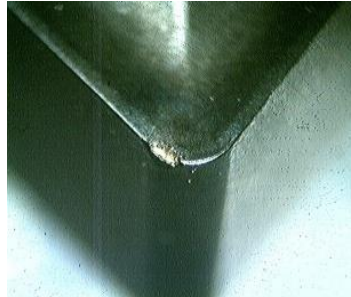

Run-4

$(\mathrm{d}=0.1 \mathrm{~mm}$,

$\mathrm{f}=0.16 \mathrm{~mm} / \mathrm{rev}$,

$\mathrm{v}=190 \mathrm{~m} / \mathrm{min}$ )

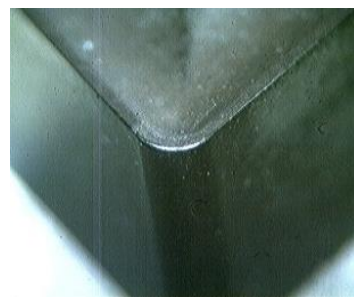

Run-12

$(\mathrm{d}=0.3 \mathrm{~mm}$,

$\mathrm{f}=0.16 \mathrm{~mm} / \mathrm{rev}$,

$\mathrm{v}=110 \mathrm{~m} / \mathrm{min}$ )

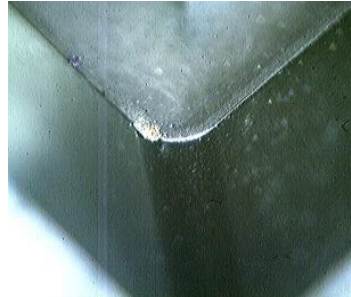

Run-5

(d= $0.2 \mathrm{~mm}$,

$\mathrm{f}=0.04 \mathrm{~mm} / \mathrm{rev}$,

$\mathrm{v}=110 \mathrm{~m} / \mathrm{min}$ )

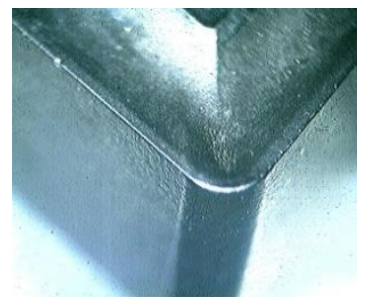

Run-13

$(\mathrm{d}=0.4 \mathrm{~mm}$, $\mathrm{f}=0.04 \mathrm{~mm} / \mathrm{rev}$,

$\mathrm{v}=190 \mathrm{~m} / \mathrm{min}$ )

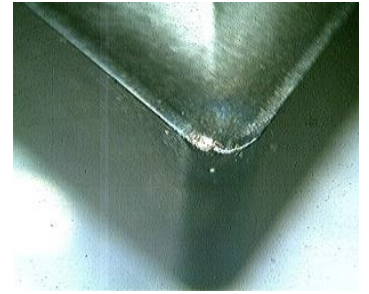

Run-8

$(\mathrm{d}=0.2 \mathrm{~mm}$, $\mathrm{f}=0.16 \mathrm{~mm} / \mathrm{rev}$,

$\mathrm{v}=150 \mathrm{~m} / \mathrm{min}$ )

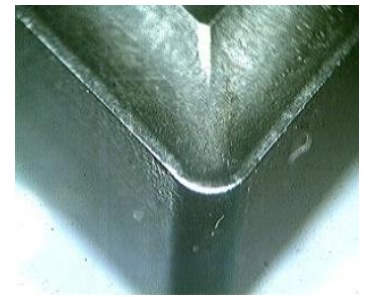

Run-16

$(\mathrm{d}=0.4 \mathrm{~mm}$, $\mathrm{f}=0.16 \mathrm{~mm} / \mathrm{rev}$, $\mathrm{v}=70 \mathrm{~m} / \mathrm{min}$ )

Figure 3. Evolutions of flank wear at various runs (run no. 1, 4, 5, 8, 9, 12, 13, 16).

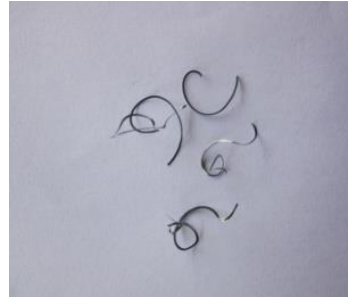

\section{Run-1}

$(\mathrm{d}=0.1 \mathrm{~mm}$,

$\mathrm{f}=0.04 \mathrm{~mm} / \mathrm{rev}$,

$\mathrm{v}=70 \mathrm{~m} / \mathrm{min}$ )

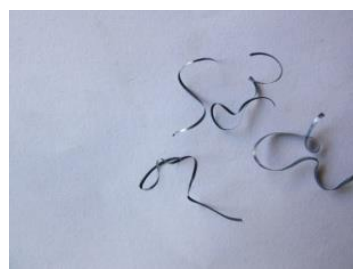

Run-9

$(\mathrm{d}=0.3 \mathrm{~mm}$,

$\mathrm{f}=0.04 \mathrm{~mm} / \mathrm{rev}$,

$\mathrm{v}=150 \mathrm{~m} / \mathrm{min}$ )

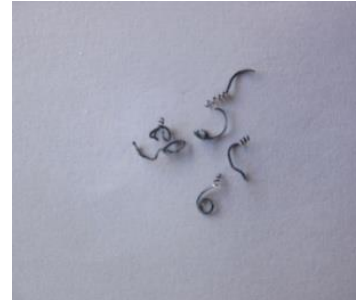

\section{Run-4}

$(\mathrm{d}=0.1 \mathrm{~mm}$,

$\mathrm{f}=0.16 \mathrm{~mm} / \mathrm{rev}$,

$\mathrm{v}=190 \mathrm{~m} / \mathrm{min}$ )

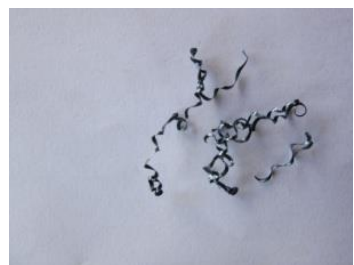

\section{Run-12}

(d=0.3 mm,

$\mathrm{f}=0.16 \mathrm{~mm} / \mathrm{rev}$,

$\mathrm{v}=110 \mathrm{~m} / \mathrm{min}$ )

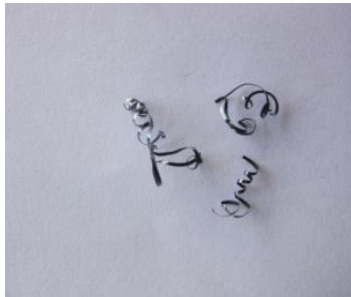

\section{Run-5}

$(\mathrm{d}=0.2 \mathrm{~mm}$,

$\mathrm{f}=0.04 \mathrm{~mm} / \mathrm{rev}$,

$\mathrm{v}=110 \mathrm{~m} / \mathrm{min}$ )

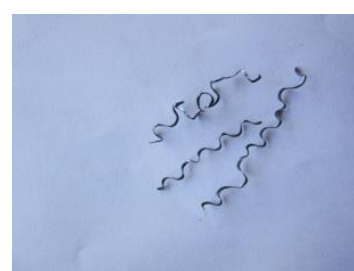

\section{Run-13}

$(\mathrm{d}=0.4 \mathrm{~mm}$,

$\mathrm{f}=0.04 \mathrm{~mm} / \mathrm{rev}$,

$\mathrm{v}=190 \mathrm{~m} / \mathrm{min}$ )

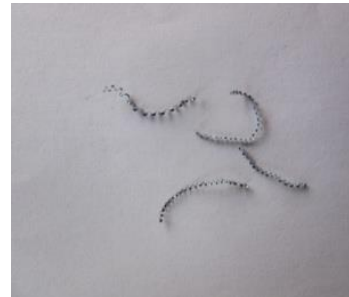

\section{Run-8}

$(\mathrm{d}=0.2 \mathrm{~mm}$,

$\mathrm{f}=0.16 \mathrm{~mm} / \mathrm{rev}$,

$\mathrm{v}=150 \mathrm{~m} / \mathrm{min}$ )

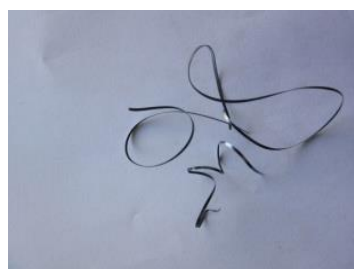

\section{Run-16}

$(\mathrm{d}=0.4 \mathrm{~mm}$,

$\mathrm{f}=0.16 \mathrm{~mm} / \mathrm{rev}$,

$\mathrm{v}=70 \mathrm{~m} / \mathrm{min}$ )

Figure 4. Images of chip at various runs (run no. 1, 4, 5, 8, 9, 12, 13, 16).

The vital effect of flank wear is concluded to be due to abrasion in character from the investigated range. In conclusions, multilayer $\left(\mathrm{TiN} / \mathrm{TiCN} / \mathrm{Al}_{2} \mathrm{O}_{3}\right)$ coated carbide tool 
has the ability to machine hardened AISI 52100 steel at 55 HRC hardness level under dry environment at chosen parametric cutting conditions even at higher cutting speed-feeddepth of cut combinations. The improved performance is attributed due to the presence of top thermal barrier property coating of $\mathrm{Al}_{2} \mathrm{O}_{3}$ and because of which more generated heat is accumulated on the workpiece rather than cutting tool and thus prevents the growth of flank wear of the inserts. Secondly, additional wear resistant coating of TiCN followed by lubricious TiN coating (diffusion barrier coating) reduces the friction and prevents interface temperature thus delays the evolution of tool wear. Thus, the combination of the presence of hard thin layer coatings on carbide substrate such as thermal barrier due to $\mathrm{Al}_{2} \mathrm{O}_{3}$ thus provides crater wear resistance due to high temperature conditions and hardness, wear resistant and thermal stability due to TiCN and diffusion barrier (heat resistant) with low coefficient of friction as a result of TiN provides the retention of cutting insert hardness at enhanced temperature and performed better also at extreme parametric range.

From the main effect plot Figure 5 (a), it is revealed that growth of wear at the flank surface with rise of cutting speed, feed and depth of cut respectively. In fact, the increase of flank wear is of slower rate with the rise of feed and depth of cut in machining. The impact of cutting speed is more predominant and sharp rise of flank wear is noticed at larger cutting speed of $190 \mathrm{~m} / \mathrm{min}$ from the main effect plot. ANOVA is studied to generate the compelling parameters affecting flank wear in hard machining and the Table 3 is constructed at $95 \%$ confidence level. The probability of significance (P-value) indicates the statistical significance of parameter if its value is below 0.05. The ANOVA table indicates that cutting speed is the most dominating parameter on flank wear as its value is 0.000 and feed and depth of cut do not show any mathematical significance on wear on the flank surface. Further, interaction of feed-depth of cut is also dependent on flank wear from the interaction plot Figure5 (b).

Table 3. Analysis of variance for flank wear.

\begin{tabular}{ccccccc}
\hline Source & DF & SS & MS & F & P & Remarks \\
\hline $\mathrm{d}$ & 3 & 0.0014 & 0.0004 & 2.49 & 0.158 & Insignificant \\
$\mathrm{f}$ & 3 & 0.002 & 0.0006 & 3.61 & 0.085 & Insignificant \\
$\mathrm{v}$ & 3 & 0.0186 & 0.0062 & 32.24 & 0.000 & Significant \\
Error & 6 & 0.0011 & 0.0001 & & & \\
Total & 15 & 0.0233 & & & & \\
$\mathrm{~S}=0.013$ & & $\mathrm{R}-\mathrm{sq}=95.04 \%$ & & & & \\
\hline
\end{tabular}




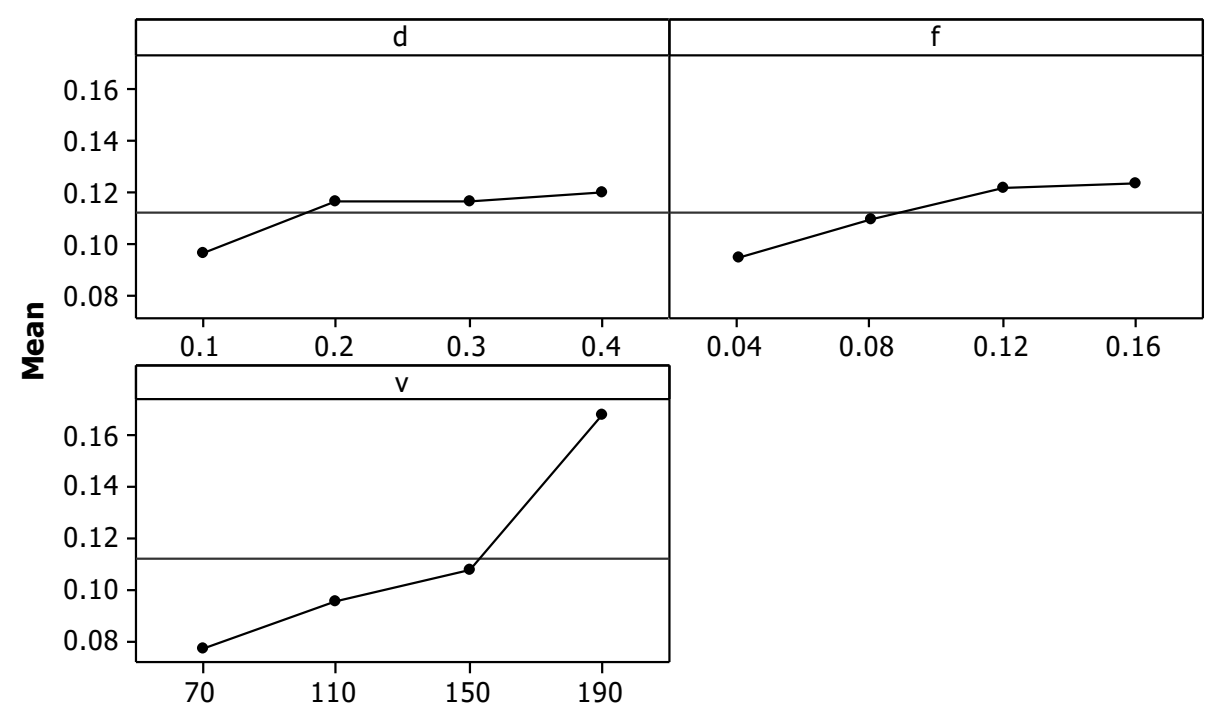

(a)

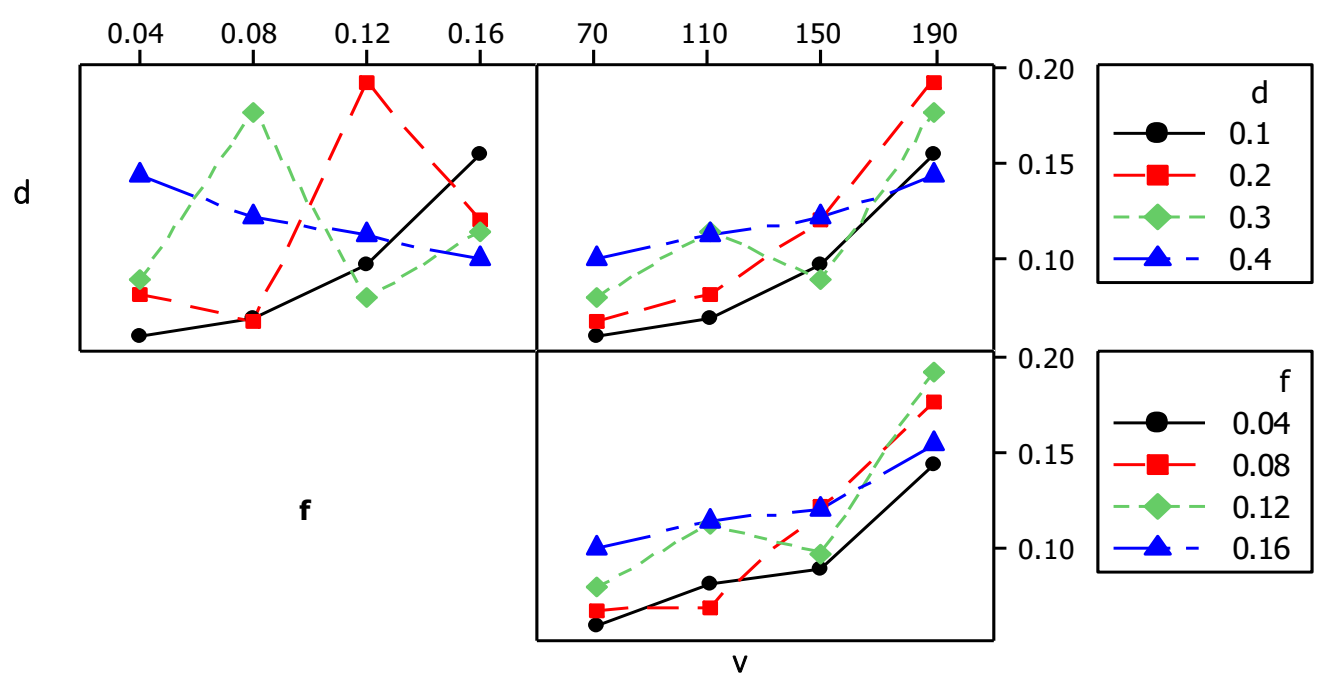

(b)

Figure 5 (a) Main effect plot and; (b) interaction plot of flank wear.

\section{Analysis of Chip Morphology}

Chips are collected at different runs and analyzed its morphology to examine the essence of interactions at the chip-tool interface as cutting temperature increases in hard turning which reduces the tool life and surface quality of the specimen. The images of chip samples are shown in Figure 4 and presented in Table 2. Chip samples are helical type with metallic grey colour in majority of runs which shows the reduction of cutting temperature in hard turning and it is due to the presence of thermal barrier coatings $\left(\mathrm{Al}_{2} \mathrm{O}_{3}\right)$ in multilayer coated carbide inserts. This helps in maintaining the sharpness of the cutting tool without any plastic deformation of cutting edges and thus reduces the growth of tool wear. But at higher cutting speed i.e. at $150 \mathrm{~m} / \mathrm{min}$ and $190 \mathrm{~m} / \mathrm{min}$, blue colour saw tooth chips are obtained which reveals the increase of cutting temperature during hard machining and thus accelerates the tool wear. Saw-tooth chips at more cutting 
speed are due to localized deformation in the primary shear zone and catastrophic shear as material tends to brittle [32]. Thus, mechanism related to formation of chip in machining of hardened material is the marks the initiation of crack and slip. From the chip morphology analysis, it is concluded that multilayer coated carbide insert generates reduced temperature while machining hardened AISI 52100 steel and maintains cutting edge sharpness and delays the growth of tool wear.

\section{Analysis of Surface Roughness}

The surface roughness is measured at successive runs under various parametric ranges in hard machining and are presented in Table 2. The measured surface roughness varies from 0.2 microns to 1.33 microns respectively which is below the criterion limit of 1.6 microns. [20, 29, 30, 31] This justifies its implementation in hard turning as surface roughness values are comparable to traditional grinding operation and may be replaced. A good surface quality is obtained by the application of carbide inserts with multiple layers even at elevated parametric ranges.

From main effect plot Figure 6 (a), it is noticeable that surface roughness rises with the rise of feed. This is mainly due to elevated friction among work piece and tool. However, it increases with a slower rate from $0.04 \mathrm{~mm} / \mathrm{rev}$ to $0.12 \mathrm{~mm} / \mathrm{rev}$ and then sharp rise of surface quality is noticed with the rise of feed from $0.12 \mathrm{~mm} / \mathrm{rev}$ to $0.16 \mathrm{~mm} / \mathrm{rev}$. This may be owing to the induced vibrations in hard machining and consequently degrades the surface quality at higher feed. Interesting observations shows that even if at higher feed, surface roughness obtained is quite less than 1.6 microns in all experiments using coated carbide tool having multiple layers in machining of hardened material. The surface quality demises with the rise of cutting speed from $70 \mathrm{~m} / \mathrm{min}$ to $110 \mathrm{~m} / \mathrm{min}$ and this may be attributed owing to the drop of cutting forces in hard machining which brings stability of the machining systems. But at higher cutting speed at $150 \mathrm{~m} / \mathrm{min}$, surface roughness increases at a marginal rate and increases further to a greater extent at 190 $\mathrm{m} / \mathrm{min}$ cutting speed because of rapid tool wear. It is interesting to note that surface roughness is below acceptable limit of 1.6 microns even if at higher cutting speed during hard machining. The experimental findings reveal that surface roughness decreases with the rise of depth of cut but at a slower rate within 0.6 microns to 0.8 microns and their difference is marginal. This may be concluded that depth of cut does not have enough sway on surface finish in hard machining and its magnitude is much below 1.6 microns at any combinations of feed cutting speed chosen in the research. Feed is noted to be the utmost significant factor to control the surface quality as their P-value is lower than 0.05 and statistically compelling. Cutting speed and depth of cut do not show any compelling contributions on surface roughness from the ANOVA study (similar to Table 3). Besides, interactions of cutting speed-feed, depth of cut-feed and cutting speed-depth of cut are also dependent on surface roughness from the interaction plot Figure 6 (b). 


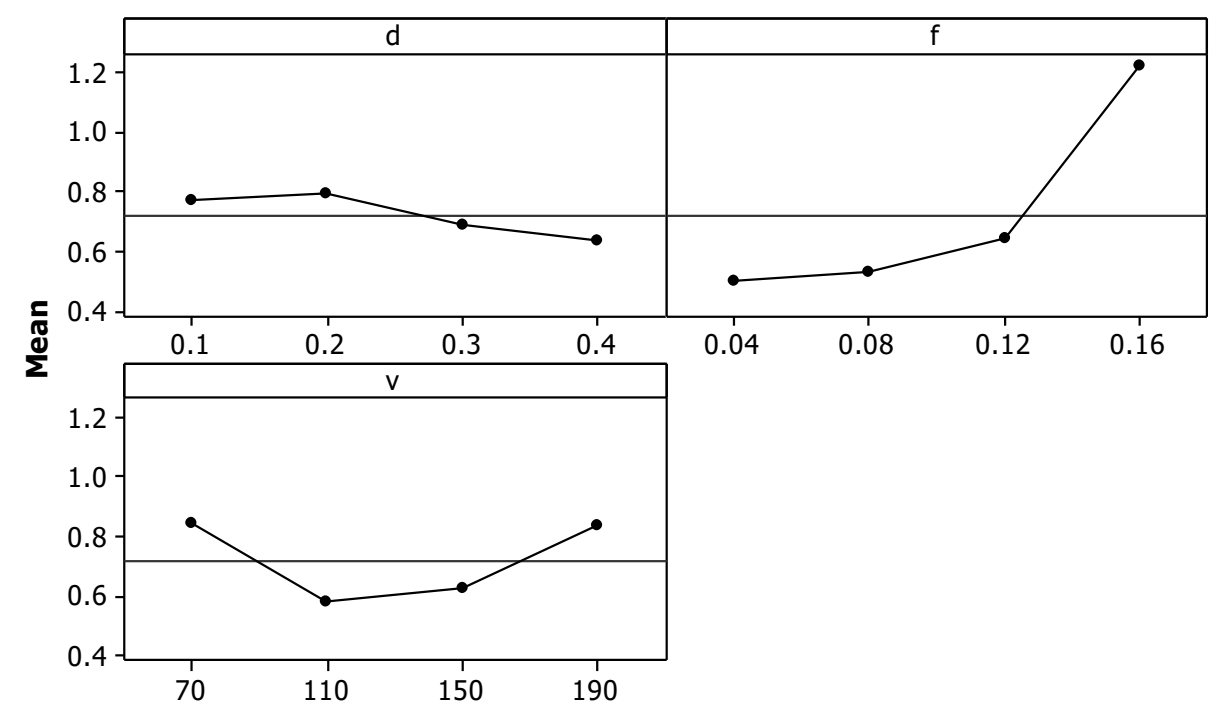

(a)

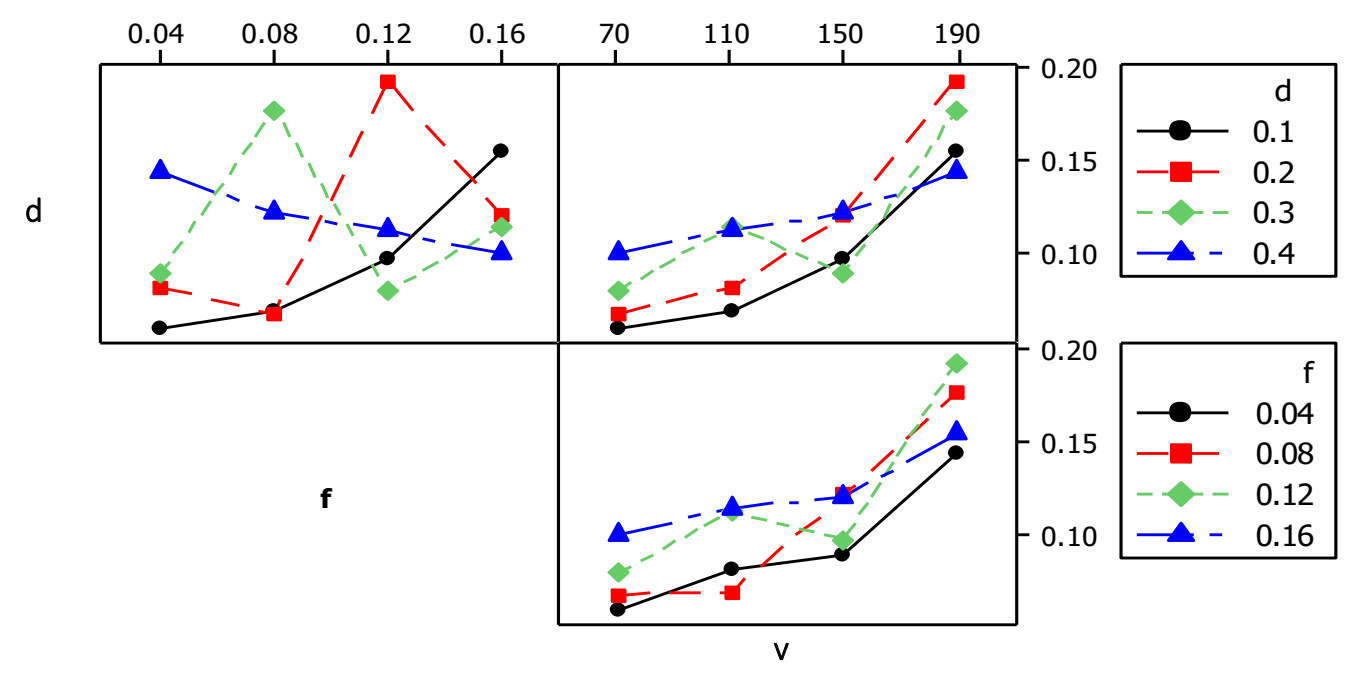

(b)

Figure 6 (a). Main effect plot and; (b). interaction plot of surface roughness.

Keeping an eye of outperformance of coated carbide insert with multiple layers in turning operation of AISI 52100 grades steel, further investigations on mathematical and artificial neural network modeling, multi-response parametric optimization and study on tool life at optimal level have been carried out and presented below.

\section{QR and ANN Model in Hard Turning}

\section{Quadratic regression model}

Quadratic regression $(\mathrm{QR})$ model of second order has been developed for both responses such as flank wear $(\mathrm{VBc})$ and surface roughness $(\mathrm{Ra})$ as a function of input variables i.e. depth of cut (d), feed (f) and cutting speed (v) at $95 \%$ confidence level. The mathematical significance of model as well as terms in the model has been checked by their respective 
P-value (probability of significance). The developed mathematical equations for $\mathrm{VBc}$ and $\mathrm{Ra}$ are shown as in Eq. (1) and (2).

$$
\begin{aligned}
& \mathrm{VBc}=0.1163-0.0165 \mathrm{~d}-0.4814 \mathrm{f}-0.0011 \mathrm{v}-0.4062 \mathrm{~d}^{2}-2.1484 \mathrm{f}^{2}+ \\
& 0.0000 \mathrm{v}^{2}+2.9858 \mathrm{df}+0.0003 \mathrm{dv}+0.0033 \mathrm{fv} \\
& \mathrm{R}^{2}=98.58 \%, \mathrm{R}^{2}(\text { Pred })=83.51 \%, \mathrm{R}^{2}(\operatorname{adj})=96.44 \% \\
& \mathrm{Ra}=3.921-7.7006 \mathrm{~d}-25.517 \mathrm{f}-0.0306 \mathrm{v}-1.625 \mathrm{~d}^{2}+85.9375 \mathrm{f}^{2}+0.0001 \\
& \mathrm{v}^{2}+39.6591 \mathrm{df}+0.0374 \mathrm{dv}+0.0577 \mathrm{fv} \\
& \mathrm{R}^{2}=97.76 \%, \mathrm{R}^{2}(\text { Pred })=70.25 \%, \mathrm{R}^{2}(\operatorname{adj})=94.41 \%
\end{aligned}
$$

The developed models for both $\mathrm{VBc}$ and Ra have higher value of determination coefficients $\left(\mathrm{R}^{2}\right.$ value) showing significance of model as it approaches to one and model ANOVA indicates statistically importance also because of P-value is lower than 0.05 (Table 4 and 5). That reveals the goodness of fitting of the developed models. From analysis of variance of models developed, a few of the linear, square and interaction terms are noted to be statistically incompelling as their P-value is more than 0.05 . Therefore, by deleting the insignificant terms from the model, the reduced quadratic regression model for both VBc and Ra becomes Eq. (3) and (4).

$$
\begin{aligned}
& \mathrm{VBc}=0.1163-0.0011 \mathrm{v}-+0.0000 \mathrm{v}^{2}+2.9858 \mathrm{df} \\
& \mathrm{Ra}=3.921-7.7006 \mathrm{~d}-25.517 \mathrm{f}-0.0306 \mathrm{v}+85.9375 \mathrm{f}^{2}+0.0001 \mathrm{v}^{2}+39.6591 \\
& \mathrm{df}+0.0374 \mathrm{dv}+0.0577 \mathrm{fv}
\end{aligned}
$$

Table 4. Results of ANOVA for flank wear model.

\begin{tabular}{cccccccc}
\hline Source & DF & Seq SS & Adj SS & Adj MS & F & P & Remarks \\
\hline Regression & 9 & 0.023 & 0.023 & 0.0025 & 46.15 & 0.000 & Significant \\
Linear & 3 & 0.0192 & 0.0005 & 0.0001 & 3.4 & 0.094 & \\
d & 1 & 0.001 & 0.0000 & 0.0000 & 0.01 & 0.911 & \\
f & 1 & 0.0018 & 0.0001 & 0.0001 & 1.85 & 0.223 & \\
v & 1 & 0.0163 & 0.0005 & 0.0005 & 9.07 & 0.024 & \\
Square & 3 & 0.0022 & 0.0022 & 0.0007 & 13.46 & 0.005 & \\
$\mathrm{~d}^{2}$ & 1 & 0.0002 & 0.0002 & 0.0002 & 4.76 & 0.072 & \\
$\mathrm{f}^{2}$ & 1 & 0.0001 & 0.0001 & 0.0001 & 3.41 & 0.114 & \\
$\mathrm{v}^{2}$ & 1 & 0.0017 & 0.0017 & 0.0017 & 32.2 & 0.001 & \\
Interaction & 3 & 0.0015 & 0.0015 & 0.0005 & 9.16 & 0.012 & \\
$\mathrm{~d}^{*} \mathrm{f}$ & 1 & 0.0012 & 0.0012 & 0.0012 & 22.64 & 0.003 & \\
$\mathrm{~d}^{*} \mathrm{v}$ & 1 & 0.0000 & 0.0000 & 0.0000 & 0.26 & 0.627 & \\
$\mathrm{f}^{*} \mathrm{v}$ & 1 & 0.0002 & 0.0002 & 0.0002 & 4.59 & 0.076 & \\
Residual & 6 & 0.0003 & 0.0003 & 0.0000 & & & \\
Error & & & & & & & \\
Total & 15 & 0.0233 & & & & &
\end{tabular}


Table 5. Results of ANOVA for surface roughness model.

\begin{tabular}{cccccccc}
\hline Source & DF & Seq SS & Adj SS & Adj MS & F & P & Remarks \\
\hline Regression & 9 & 2.1177 & 2.1177 & 0.2353 & 29.16 & 0.000 & Significant \\
Linear & 3 & 1.0963 & 0.7012 & 0.2337 & 28.96 & 0.001 & \\
d & 1 & 0.052 & 0.164 & 0.164 & 20.33 & 0.004 & \\
f & 1 & 1.0442 & 0.2881 & 0.2881 & 35.71 & 0.001 & \\
v & 1 & 0.0000 & 0.3565 & 0.3564 & 44.17 & 0.001 & \\
Square & 3 & 0.5276 & 0.5276 & 0.1758 & 21.79 & 0.001 & \\
$\mathrm{~d}^{2}$ & 1 & 0.0042 & 0.0042 & 0.0042 & 0.52 & 0.497 & \\
$\mathrm{f}^{2}$ & 1 & 0.3025 & 0.3025 & 0.3025 & 37.48 & 0.001 & \\
$\mathrm{v}^{2}$ & 1 & 0.2209 & 0.2209 & 0.2209 & 27.37 & 0.002 & \\
Interaction & 3 & 0.4937 & 0.4937 & 0.1645 & 20.39 & 0.002 & \\
$\mathrm{~d}^{*} \mathrm{f}$ & 1 & 0.2214 & 0.2214 & 0.2214 & 27.44 & 0.002 & \\
$\mathrm{~d}^{*} \mathrm{v}$ & 1 & 0.1974 & 0.1974 & 0.1974 & 24.46 & 0.003 & \\
$\mathrm{f}^{*} \mathrm{v}$ & 1 & 0.0749 & 0.0749 & 0.0749 & 9.28 & 0.023 & \\
Residual & 6 & 0.0484 & 0.0484 & 0.008 & & & \\
Error & & & & & & & \\
Total & 15 & 2.1661 & & & & &
\end{tabular}

The normal probability plot indicates that the residuals are dispersed normally and fall close to the straight line for both the models developed and shown in Figure7 (a) and (b) and thus shows the significance characteristics. Furthermore, contour plots are curvilinear profile satisfies second order models fitted and helps to find out the domain where minimum flank wear and surface finish are obtained Figure 8 (a) and (b). Contour plots shows that low levels of depth of cut, feed and cutting speed yields minimal flank wear and surface finish values.

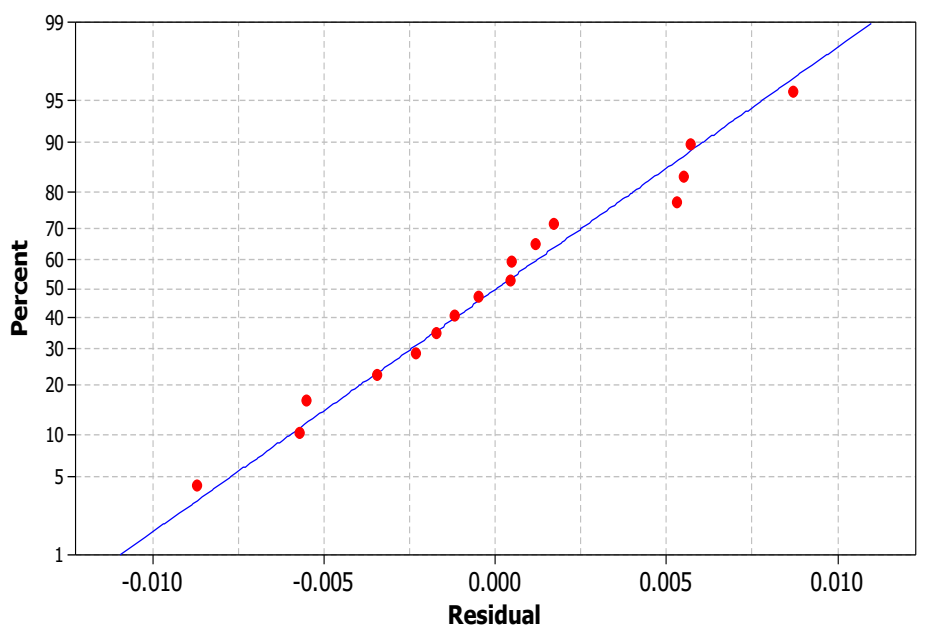

(a) 


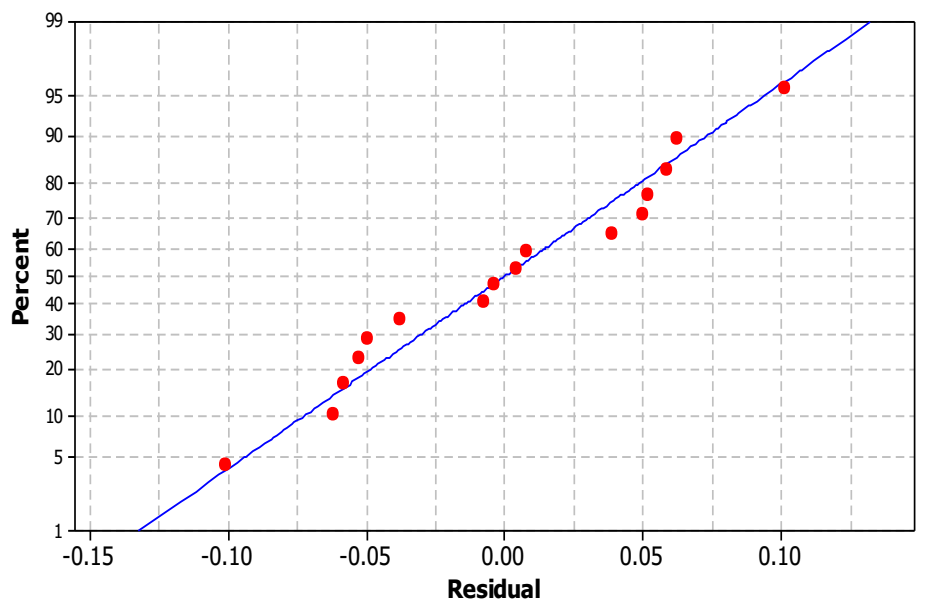

(b)

Figure 7. Normal probability plot of residuals for (a) flank wear and; (b) surface roughness
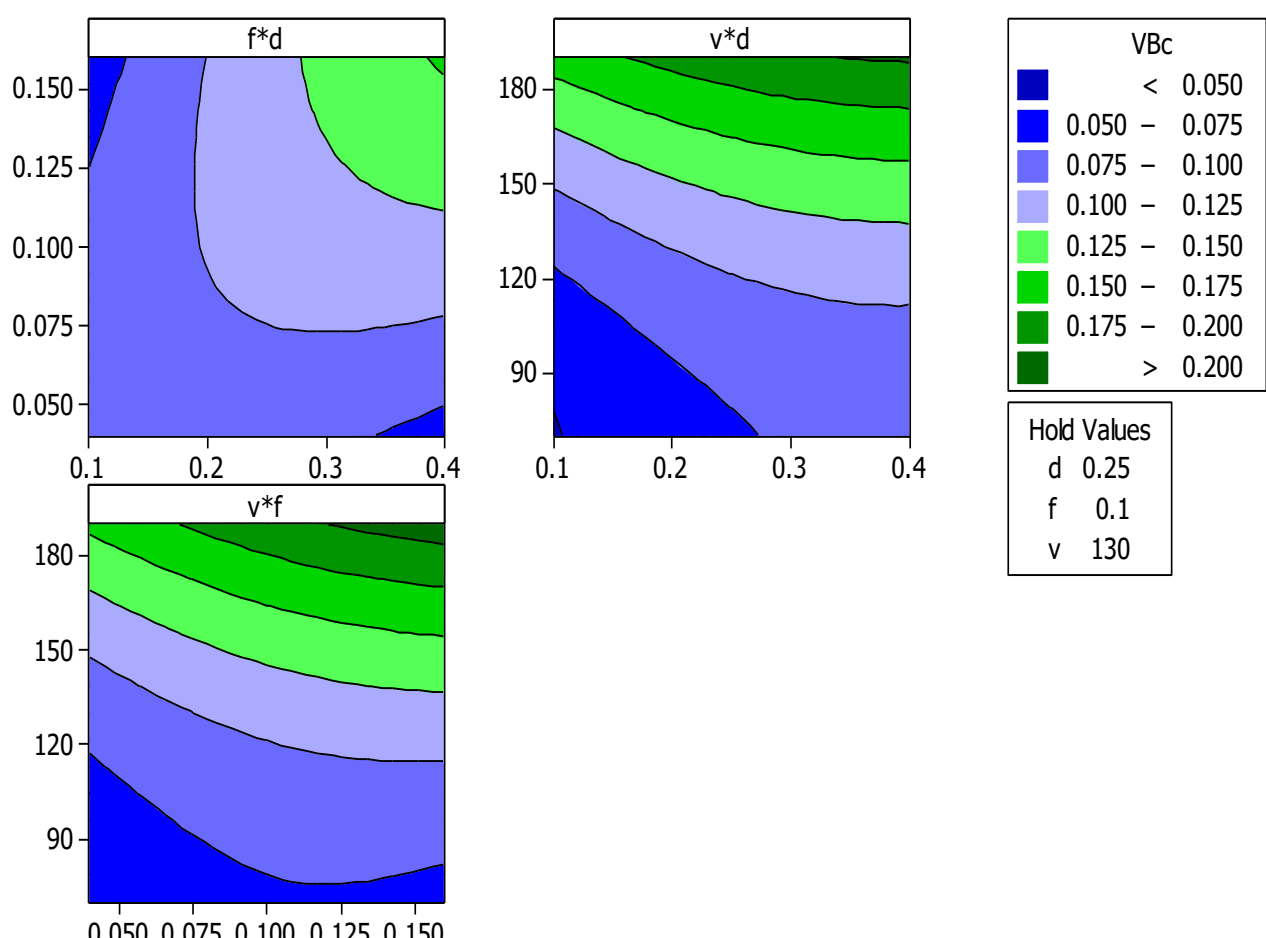

(a) 

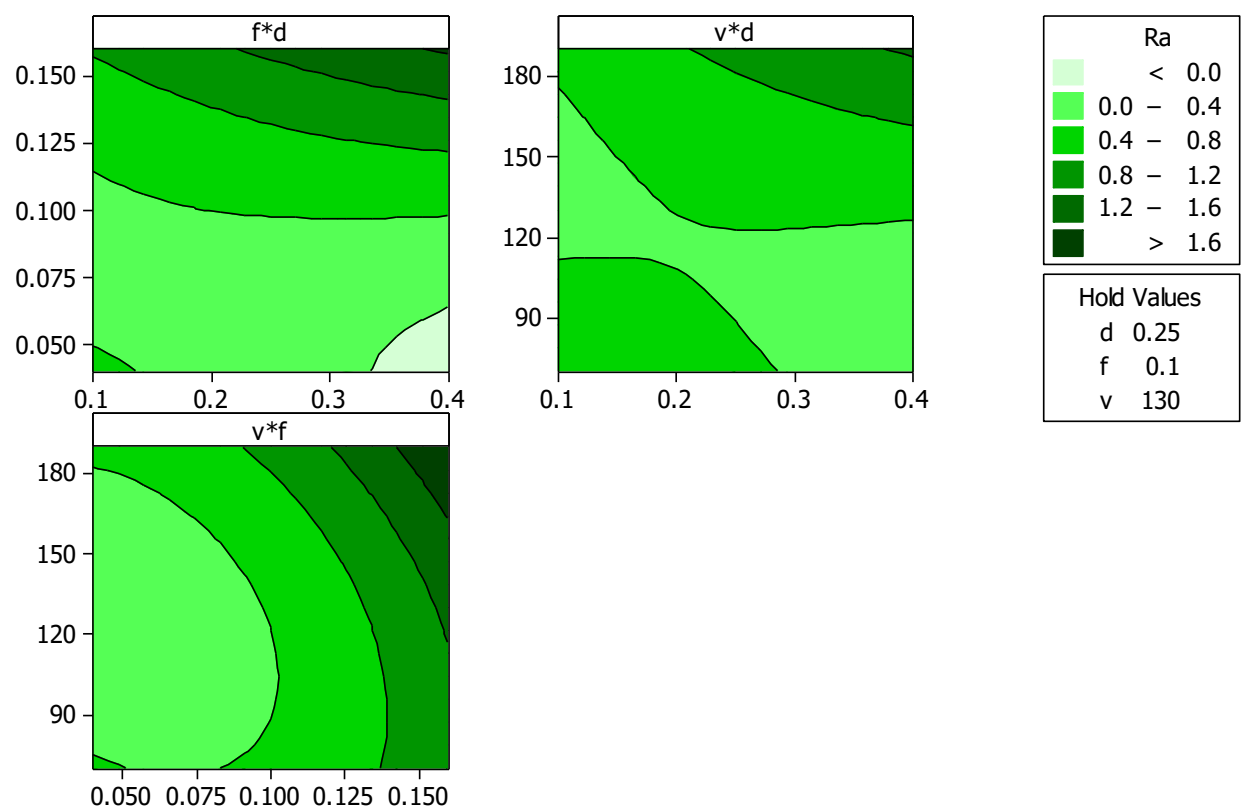

(b)

Figure 8. Contour plot of (a) flank wear and; (b) surface roughness.

\section{Artificial neural network model}

Artificial neural networks are now widely applied in various industrial situations and found to be effective in predicting the responses by developing the model, optimization, system identification and pattern recognition [33]. ANN is potential and suitable to adapt complex non-linear and multivariable relations between machining variables and inspect their effects on responses such as surface roughness and flank wear [34, 35]. Basically, an artificial neural network in this paper is adapted to estimate the flank wear and surface roughness in hard turning. It is a cross linked system having processing unit called neurons. The input layer, hidden layer and output layer that are parts of network are connected in series with a weight factor. The neural network is trained by varying the weight factors. To obtain the correlations between input and output, the experimental data are used to train the ANN. A multilayered feed forward network of the input and output neurons was used with the Levenberg-Marquardt back propagation algorithm and trained through the experimental results [36]. The network was trained with approximately $80 \%$ of experimental data. Based on the least error criterion, the quantity of neurons in the covert layer was optimized to seven as shown in Figure 9 (a) and (b) respectively. Table 6 and 7 yields the output data using the minimum average error criterion for prediction of flank wear and surface roughness respectively. There is a competent correlation among the experimental values and predicted values from the models (both QR and ANN) which is shown in Figure 10 (a) and (b). However, ANN model is found to be very close to experimental value. The percentage of error is calculated by using Eq. (5).

$\%$ of error $=[($ Experimental value - predicted value $) /$ Experimental value $] \times 100$ 


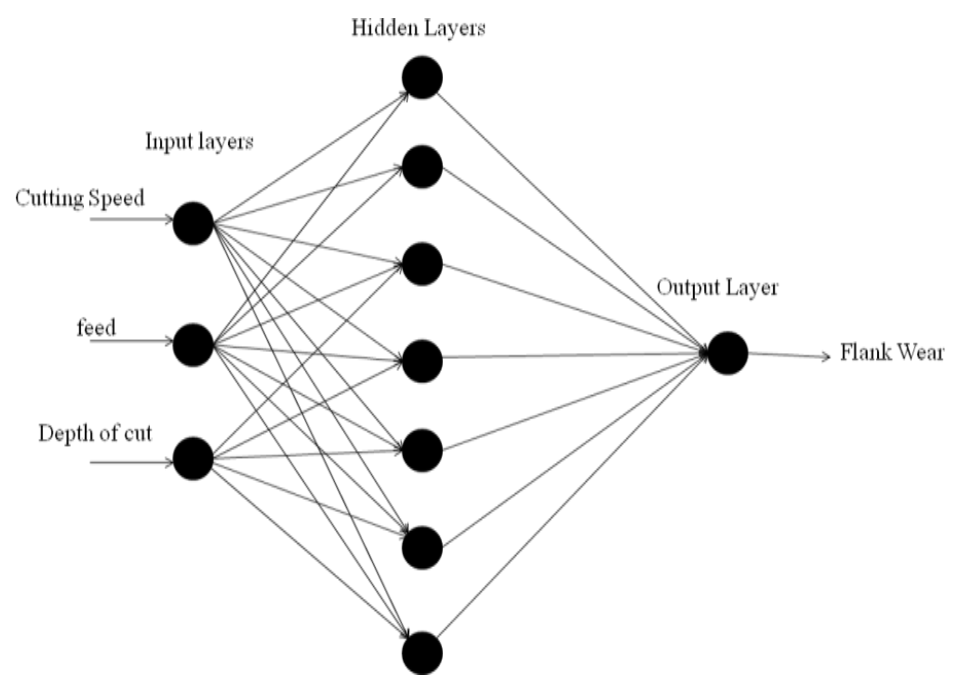

(a)

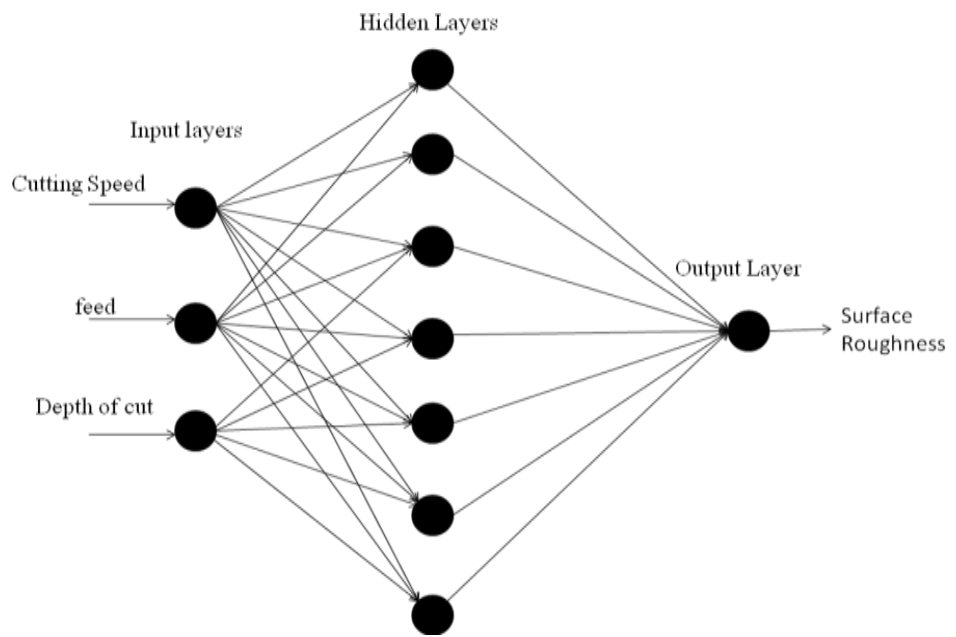

(b)

Figure 9. Network diagram of ANN for (a) flank wear and; (b) surface roughness.

Table 6. Input parameters selected for training for flank wear.

\begin{tabular}{ll}
\hline Input parameter for training & Values \\
\hline Error tolerance & 0.001 \\
Learning rate $(\beta)$ & 0.1 \\
Momentum parameter $(\alpha)$ & 0.01 \\
Noise factor $(\mathrm{NF})$ & 0.001 \\
Number of epochs & $20,00,000$ \\
Slope parameter $(\mathrm{k})$ & 0.6 \\
Number of hidden layer neuron $(\mathrm{H})$ & 7 \\
Number of input layer neuron $(\mathrm{I})$ & 3 \\
Number of output layer neuron $(\mathrm{O})$ & 1 \\
\hline
\end{tabular}


Table 7. Input parameters selected for training for surface roughness.

\begin{tabular}{ll}
\hline Input parameter for training & Values \\
\hline Error tolerance & 0.001 \\
Learning rate $(\beta)$ & 0.2 \\
Momentum parameter $(\alpha)$ & 0.01 \\
Noise factor $(\mathrm{NF})$ & 0.001 \\
Number of epochs & $20,00,000$ \\
Slope parameter $(\mathrm{k})$ & 0.53 \\
Number of hidden layer neuron $(\mathrm{H})$ & 7 \\
Number of input layer neuron $(\mathrm{I})$ & 3 \\
Number of output layer neuron $(\mathrm{O})$ & 1 \\
\hline
\end{tabular}

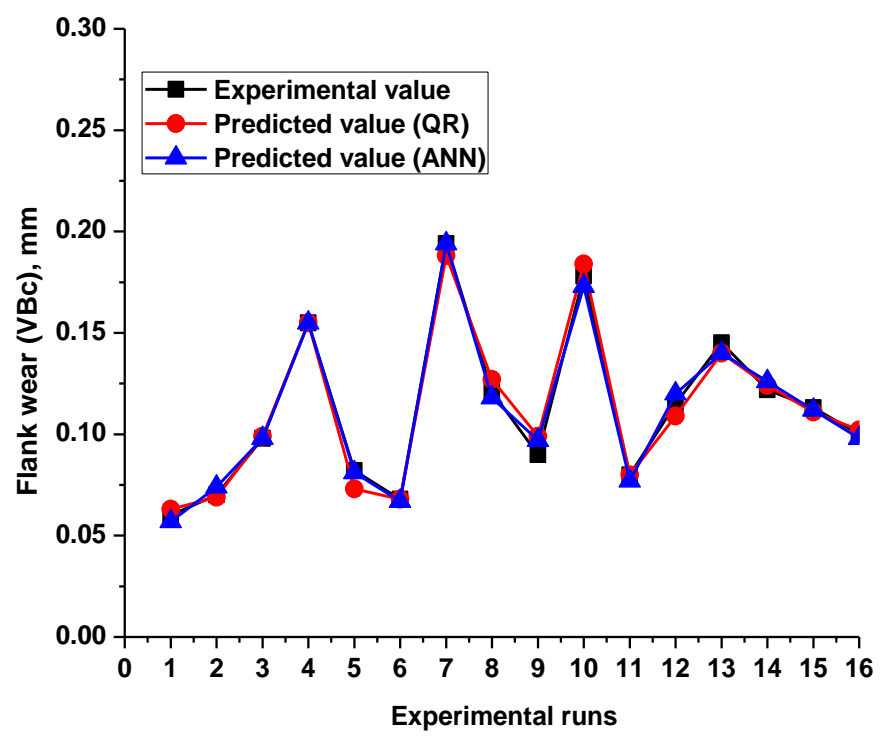

(a)

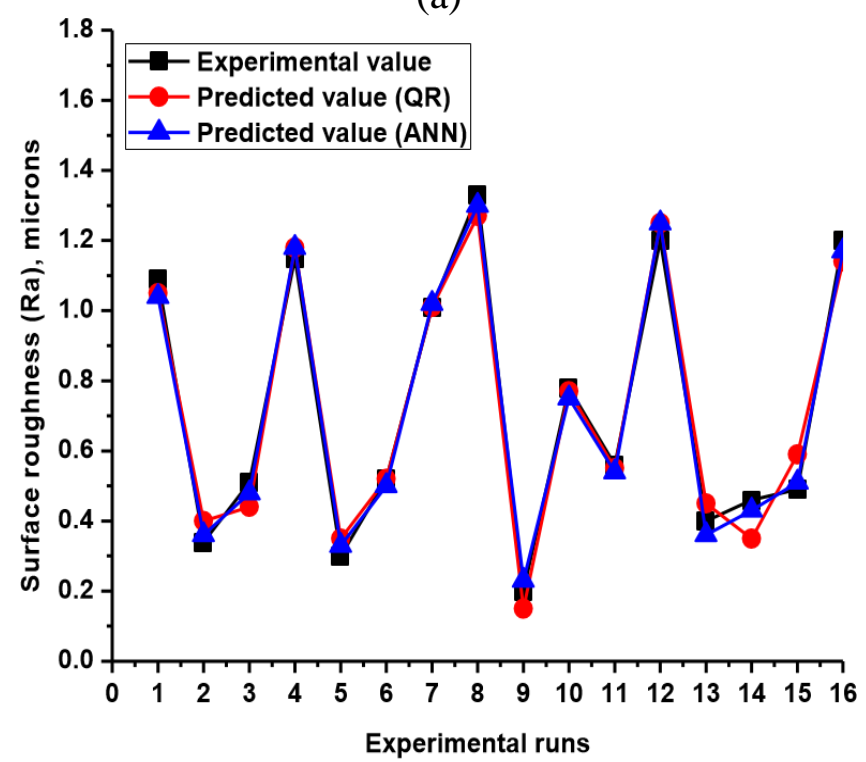

(b)

Figure 10. Comparison between experimental, QR and ANN results for (a) flank wear and; (b) surface roughness. 
The maximum percentage of error for flank wear is found to be 10.97 for QR model compared to 5.71 in ANN model (Table 8). Similarly, for surface roughness, maximum percentage of error is 23.91 for QR model in comparison to 6.52 in ANN model (Table 9). Comparing both the models, ANN model represents most appropriate forecast of both responses with minimum average error percentage i.e. 2.75 for $\mathrm{VBc}$ and 5.35 for $\mathrm{Ra}$ compared to quadratic regression (QR) model i.e. 3.36 for $\mathrm{VBc}$ and 9.55 for $\mathrm{Ra}$ respectively. Thus, ANN model may be implemented for accurate prediction of wear at the flank surface and surface quality during turning of heat treated AISI 52100 grade steel within and beyond the experimental domain.

Table 8. Comparison of experimental, QR and ANN results and \% of error for flank wear.

\begin{tabular}{cccccc}
\hline Run & \multicolumn{5}{c}{ Flank wear, VBc $(\mathrm{mm})$} \\
\cline { 2 - 6 } & Experimental & QR & ANN & \% of error $(\mathrm{QR})$ & \% of error (ANN) \\
\hline 1 & 0.060 & 0.063 & 0.057 & -5 & 5 \\
2 & 0.070 & 0.069 & 0.074 & 1.42 & -5.71 \\
3 & 0.098 & 0.099 & 0.098 & -1.02 & 0.00 \\
4 & 0.155 & 0.155 & 0.155 & 0.00 & 0.00 \\
5 & 0.082 & 0.073 & 0.081 & 10.97 & 1.21 \\
6 & 0.068 & 0.068 & 0.067 & 0.00 & 1.47 \\
7 & 0.194 & 0.188 & 0.194 & 3.09 & 0.00 \\
8 & 0.121 & 0.127 & 0.118 & -4.95 & 2.47 \\
9 & 0.090 & 0.099 & 0.097 & -10 & -7.77 \\
10 & 0.178 & 0.184 & 0.173 & -3.37 & 2.80 \\
11 & 0.080 & 0.08 & 0.077 & 0.00 & 3.75 \\
12 & 0.115 & 0.109 & 0.120 & 5.21 & -4.34 \\
13 & 0.145 & 0.14 & 0.140 & 3.44 & 3.44 \\
14 & 0.122 & 0.124 & 0.126 & -1.63 & -3.27 \\
15 & 0.113 & 0.111 & 0.112 & 1.76 & 0.88 \\
16 & 0.100 & 0.102 & 0.098 & -2 & 2 \\
& & & & Average \% of error $=$ & Average $\%$ of \\
& & & & 3.36 & error $=2.75$ \\
\hline
\end{tabular}

Table 9. Comparison of experimental, QR and ANN results and \% of error for surface roughness.

\begin{tabular}{cccccc}
\hline \multirow{2}{*}{ Run } & \multicolumn{5}{c}{ Surface roughness, Ra $(\mu \mathrm{m})$} \\
\cline { 2 - 6 } & Experimental & QR & ANN & \% of error $(\mathrm{QR})$ & $\begin{array}{l}\text { \% of error } \\
(\text { ANN) }\end{array}$ \\
\hline 1 & 1.09 & 1.05 & 1.04 & 3.66 & 4.58 \\
2 & 0.34 & 0.40 & 0.36 & -17.64 & -5.88 \\
3 & 0.51 & 0.44 & 0.48 & 13.72 & 5.88 \\
4 & 1.15 & 1.18 & 1.18 & -2.6 & -2.60 \\
5 & 0.30 & 0.35 & 0.33 & -16.66 & -10 \\
6 & 0.52 & 0.52 & 0.50 & 0 & 3.84 \\
7 & 1.01 & 1.01 & 1.02 & 0 & -0.99 \\
8 & 1.33 & 1.27 & 1.30 & 4.51 & 2.25 \\
9 & 0.20 & 0.15 & 0.23 & 25 & -15
\end{tabular}


Table 9. Continue

\begin{tabular}{lccccc}
\hline 10 & 0.78 & 0.77 & 0.75 & 1.28 & 3.84 \\
11 & 0.56 & 0.55 & 0.54 & 1.78 & 3.57 \\
12 & 1.20 & 1.25 & 1.25 & -4.16 & -4.16 \\
13 & 0.40 & 0.45 & 0.36 & -12.5 & 10 \\
14 & 0.46 & 0.35 & 0.43 & -23.91 & 6.52 \\
15 & 0.49 & 0.59 & 0.51 & -20.4 & -4.08 \\
16 & 1.20 & 1.14 & 1.17 & 5 & 2.5 \\
& & & & Average $\%$ of error $=$ Average $\%$ of error \\
& & & & 9.55 & $=5.35$ \\
\hline
\end{tabular}

\section{Multi-Reponse Parametric Optimization and Assessment of Tool life}

By using grey relational analysis (GRA) coupled with Taguchi $\mathrm{L}_{16}$ orthogonal array, multi-response parametric optimization for both flank wear and surface roughness has been achieved. The methods of GRA have been applied by many researchers for simultaneous optimization of outputs and are available in literatures [37, 38, 39, 40].

Taking lower-the-better criteria, the experimental data has been normalized. Next step is to evaluate the grey relational coefficients for individual responses and they are assembling to find the grey relational grade (GRG). Table 10 shows the grey relational generation, grey relational coefficients and grey relational grade and their order respectively. Next mean grey relational grade is computed for each level of process variables i.e. $\mathrm{d}, \mathrm{f}$ and $\mathrm{v}$ and shown in Table 11. The optimal parametric combination is chosen from the higher GRG from Table 11 and found to be depth of cut of level 1 ( 0.1 $\mathrm{mm})$, feed of level $1(0.04 \mathrm{~mm} / \mathrm{rev})$ and cutting speed of level $2(110 \mathrm{~m} / \mathrm{min})$ i.e. d1-f1v2. From the ANOVA Table 12 on GRG, it is perceptible that feed is the important factor for multi-responses pursued by cutting speed as its $\mathrm{P}$-value is less than and approaches to 0.05 at $95 \%$ confidence level. Next, confirmation run has been performed to verify the improvements of GRG using initial and optimal parametric conditions and presented in Table 13. There is a compelling advancement of grey relational grade noticed from the confirmation run and observed to be 0.358. A significant decrease of flank wear and surface roughness is clearly seen taking optimal parametric conditions into consideration i.e. flank wear is of $0.063 \mathrm{~mm}$ and surface roughness of 0.76 microns which is quite less than initial parameter settings (d2-f3-v4). Thus, this optimal parametric condition may be utilized in turning of hardened AISI 52100 grade steel employing coated carbide insert having multiple layers in dry working condition.

Next step of the research is to assess the tool life of $\mathrm{Al}_{2} \mathrm{O}_{3}$ multilayer coated carbide inserts during hard turning under dry environment at optimal parametric cutting conditions. The experiment has been conducted fresh with a new cutting inserts taking $\mathrm{v}$ $(110 \mathrm{~m} / \mathrm{min})-\mathrm{f}(0.04 \mathrm{~mm} / \mathrm{rev})-\mathrm{d}(0.1 \mathrm{~mm})$ with successive intervals of machining time to observe the growth of flank wear and surface finish. The machining was paused when flank wear clocked at $0.3 \mathrm{~mm}$ and tool life is calculated. The readings after each machining intervals with successive overall machining duration was shown in Table 14 respectively. The surface roughness values at successive runs with machining time was measured and found to be less than 1 micron. 
Table 10. Grey relational generation, coefficient and grey relational grade values.

\begin{tabular}{ccccccccc}
\hline \multirow{2}{*}{ Run } & \multicolumn{2}{c}{$\begin{array}{c}\text { Grey relational } \\
\text { generation }\end{array}$} & \multicolumn{2}{c}{$\begin{array}{c}\text { Evaluation of } \\
\Delta_{0 \mathrm{i}}\end{array}$} & \multicolumn{2}{c}{$\begin{array}{c}\text { Grey relational } \\
\text { coefficient }\end{array}$} & \multirow{2}{*}{ GRG } & \multirow{2}{*}{ Rank } \\
\hline \multicolumn{2}{c}{ Ideal } & $\mathrm{VBc}$ & $\mathrm{Ra}$ & $\mathrm{VBc}$ & $\mathrm{Ra}$ & $\mathrm{VBc}$ & $\mathrm{Ra}$ & \\
sequence & 1 & 1 & 1 & 1 & 1 & 1 & & \\
\hline 1 & 1.000 & 0.212 & 0.000 & 0.788 & 1.000 & 0.388 & 0.694 & 5 \\
2 & 0.925 & 0.876 & 0.075 & 0.124 & 0.870 & 0.801 & 0.836 & 2 \\
3 & 0.716 & 0.726 & 0.284 & 0.274 & 0.638 & 0.646 & 0.642 & 7 \\
4 & 0.291 & 0.159 & 0.709 & 0.841 & 0.414 & 0.373 & 0.393 & 15 \\
5 & 0.836 & 0.912 & 0.164 & 0.088 & 0.753 & 0.850 & 0.801 & 3 \\
6 & 0.940 & 0.717 & 0.060 & 0.283 & 0.893 & 0.638 & 0.766 & 4 \\
7 & 0.000 & 0.283 & 1.000 & 0.717 & 0.333 & 0.411 & 0.372 & 16 \\
8 & 0.545 & 0.000 & 0.455 & 1.000 & 0.523 & 0.333 & 0.428 & 13 \\
9 & 0.776 & 1.000 & 0.224 & 0.000 & 0.691 & 1.000 & 0.845 & 1 \\
10 & 0.119 & 0.487 & 0.881 & 0.513 & 0.362 & 0.493 & 0.428 & 14 \\
11 & 0.851 & 0.681 & 0.149 & 0.319 & 0.770 & 0.611 & 0.690 & 6 \\
12 & 0.590 & 0.115 & 0.410 & 0.885 & 0.549 & 0.361 & 0.455 & 12 \\
13 & 0.366 & 0.823 & 0.634 & 0.177 & 0.441 & 0.739 & 0.590 & 10 \\
14 & 0.537 & 0.770 & 0.463 & 0.230 & 0.519 & 0.685 & 0.602 & 9 \\
15 & 0.604 & 0.743 & 0.396 & 0.257 & 0.558 & 0.661 & 0.610 & 8 \\
16 & 0.701 & 0.115 & 0.299 & 0.885 & 0.626 & 0.361 & 0.494 & 11 \\
\hline
\end{tabular}

Table 11. Main effects on mean grey relational grade.

\begin{tabular}{ccccccc}
\hline Factors & \multicolumn{3}{c}{ Mean Grey relational grade } & Max-Min & \multirow{2}{*}{ Rank } \\
\cline { 2 - 5 } & Level 1 & Level 2 & Level 3 & Level 4 & & \\
\hline $\mathrm{d}$ & 0.641 & 0.592 & 0.605 & 0.574 & 0.067 & 3 \\
$\mathrm{f}$ & 0.733 & 0.658 & 0.579 & 0.443 & 0.29 & 1 \\
$\mathrm{v}$ & 0.661 & 0.675 & 0.629 & 0.446 & 0.229 & 2 \\
\hline
\end{tabular}

Total mean grey relational grade $=0.6028$

Table 12. Results of ANOVA on grey relational grade.

\begin{tabular}{clllllll}
\hline Source & DF & Seq SS & Adj SS & Adj MS & F & P & Remarks \\
\hline $\mathrm{d}$ & 3 & 0.0097 & 0.0097 & 0.0032 & 0.33 & 0.802 & Insignificant \\
$\mathrm{f}$ & 3 & 0.1846 & 0.1846 & 0.0615 & 6.34 & 0.027 & Significant \\
$\mathrm{v}$ & 3 & 0.1361 & 0.1361 & 0.0453 & 4.68 & 0.052 & Insignificant \\
Error & 6 & 0.0582 & 0.0582 & 0.0097 & & & \\
Total & 15 & 0.3887 & & & & & \\
\hline
\end{tabular}


Table 13. Validation experiment.

\begin{tabular}{cccc}
\hline & Initial factor setting & \multicolumn{2}{c}{ Optimal cutting factors } \\
\cline { 3 - 4 } & & Prediction & Experiment \\
\hline Level & $\mathrm{d} 2-\mathrm{f} 3-\mathrm{v} 4$ & $\mathrm{~d} 1-\mathrm{f} 1-\mathrm{v} 2$ & $\mathrm{~d} 1-\mathrm{f} 1-\mathrm{v} 2$ \\
$\mathrm{VBc}$ & 0.194 & & 0.063 \\
$\mathrm{Ra}$ & 1.01 & & 0.76 \\
Grey relational grade & 0.372 & 1.0434 & 0.73 \\
\hline
\end{tabular}

Table 14. Tool life test at optimal parametric conditions.

\begin{tabular}{ccccccccc}
\hline $\begin{array}{c}\text { Machining } \\
\text { Time, T (min) }\end{array}$ & 2.6 & 5.1 & 7.5 & 10 & 12.5 & 15 & 17.5 & 22.5 \\
\hline $\begin{array}{c}\text { Flank wear, } \\
\text { VBc (mm) }\end{array}$ & 0.058 & 0.08 & 0.103 & 0.166 & 0.223 & 0.279 & 0.293 & 0.312 \\
\hline
\end{tabular}

The flank wear model of first order with machining time has been developed through linear regression analysis and presented in Eq. (6). Higher $\mathrm{R}^{2}$ and $\mathrm{R}^{2}$ (pred) values indicated good accuracy and fitting of model developed.

$\mathrm{VBc}=0.01774+0.0148 \mathrm{~T}$

$\mathrm{R}^{2}=93.68 \%, \mathrm{R}^{2}($ pred $)=85.06 \%, \mathrm{R}^{2}(\operatorname{adj})=92.63 \%$

As noticed from the prediction model, the flank wear outstrips the value of 0.3 $\mathrm{mm}$ when machining time reaches approximately $19 \mathrm{~min}$. Thus, the tool life of coated carbide multilayer insert ( $\mathrm{TiN} / \mathrm{TiCN} / \mathrm{Al}_{2} \mathrm{O}_{3}$ ) has been fixed to be $19 \mathrm{~min}$ at optimal parametric conditions in turning of AISI 52100 bearing steel in dry environment. The results reveal that the tool life is of reasonably maximum value and can be adopted safely in hard machining of bearing steels in industrial sectors.

\section{CONCLUSION}

The present article considered some aspects concerning to tool wear, surface quality, and chip morphology and tool life in finish turning of AISI 52100 work piece with a hardness of $55 \pm 1$ HRC using low cost (multilayer) coated carbide inserts under dry condition and developed quadratic regression and multilayered feed forward ANN model.

The multi-response optimization has been studied and evaluates the tool life at optimal parametric conditions. Hard Turning of AISI 52100 grade bearing steel with coated carbide mutilayer tool $\left(\mathrm{TiN} / \mathrm{TiCN} / \mathrm{Al}_{2} \mathrm{O}_{3}\right)$ is characterized by steady and stable machining beyond any premature failure like plastic deformation, chipping and/or catastrophic failure on the cutting edge and flank wear values are well within $0.3 \mathrm{~mm}$ criteria limit. The predominant effect of flank wear is concluded to be due to abrasion in character from the applicable range. The improved performance is attributed due to the presence of top thermal barrier property coating of $\mathrm{Al}_{2} \mathrm{O}_{3}$ and because of which more generated heat is accumulated on the workpiece rather than cutting tool and thus prevents the growth of flank wear of the inserts. The impact of cutting speed is more predominant and sharp rise of flank wear is noticed at elevated cutting speed of $190 \mathrm{~m} / \mathrm{min}$ from the main effect plot and considered as significant factor on flank wear. The measured surface 
roughness varies from 0.2 microns to 1.33 microns respectively which is below the criterion limit of 1.6 microns that can be comparable to traditional grinding operation and may be replaced. Feed is noticed to be the utmost prevalent parameter affecting surface finish. Chip samples are helical type with metallic grey colour in majority of runs which reveals the reduction of cutting temperature in machining of AISI 52100 grade steel and maintains cutting edge sharpness and delays the growth of tool wear. ANN model using multilayered feed forward network gives accurate prediction of responses with minimum error percentage compared to QR model. The optimal parametric combination through GRA approach is found to be $\mathrm{d} 1(0.1 \mathrm{~mm}) \mathrm{f} 1(0.04 \mathrm{~mm} / \mathrm{rev})-\mathrm{v} 2(110 \mathrm{~m} / \mathrm{min})$ and is greatly improved. Feed is the dominating factor for multi-responses pursued by cutting speed. Tool life of coated carbide tool with multiple layers has been found to be 19 minutes at optimal parametric conditions and thus may be adopted safely in dry turning of heat treated AISI 52100 bearing steel.

\section{ACKNOWLEDGEMENT}

The authors are grateful to Central Tool Room and Training Centre (CTTC) and KIIT, deemed to be University, Bhubaneswar, Odisha, India for extending their facilities to carry out the research work.

\section{REFERENCES}

[1] Huang Y, Chou YK, Liang YS. CBN tool wear in hard turning: a survey on research progresses. International Journal of Advanced Manufacturing Technology. 2006; 35: 443-453.

[2] O“ zel T, Karpat Y, Figueira L, Davim JP. Modelling of surface finish and tool flank wear in turning of AISI D2 steel with ceramic wiper inserts. Journal of Materials Processing Technology. 2007; 189: 192-198.

[3] Gaitonde VN, Karnik SR, Figueira L, Davim JP. Machinability investigations in hard turning of AISI D2 cold work tool steel with conventional and wiper ceramic inserts. International Journal of Refractory Metals \& Hard Materials. 2009; 27: 754763.

[4] Das SR, Dhupal D, Kumar A. Experimental investigation into machinability of hardened AISI 4140 steel using TiN coated ceramic tool. Measurement. 2015; 62: 108-126.

[5] Yallese MA, Chaoui K, Zeghib N, Boulanouar L, Rigal JF. Hard machining of hardened bearing steel using cubic boron nitride tool. Journal of Materials Processing Technology. 2009; 209: 1092-1104.

[6] Tamizharasan T, Selvaraj T, Noorul Haq A. Analysis of tool wear and surface finish in hard turning. International Journal of Advanced Manufacturing Technology. 2006; 28: 671-679.

[7] Zhang. C XP, Liu R, Yao Z. Experimental study and evaluation methodology on hard surface integrity. International Journal of Advanced Manufacturing Technology. 2006; 34(1-2): 141-148.

[8] Sahin Y. Comparison of tool life between ceramic and cubic boron nitride (CBN) cutting tools when machining hardened steels. Journal of Materials Processing Technology. 2009; 209: 3478-3489.

[9] Bouacha K, Yallese MA, Mabrouki T, Rigal J-F. Statistical analysis of surface roughness and cutting forces using response surface methodology in hard turning 
of AISI 52100 bearing steel with CBN tool. International Journal of Refractory Metals \& Hard Materials. 2010; 28: 349-361.

[10] Guddat J, M'Saoubi R, Alm P, Meyer D. Hard turning of AISI 52100 using PCBN wiper geometry inserts and the resulting surface integrity. Procedia Engineering. 2011; 19: 118-124.

[11] Mahfoudi F, Gautier L, Alain M, Abdelhadi M, Lakhdar B. High speed turning for hard material with PCBN inserts: tool wear analysis. International Journal of Machining and Machinability of Materials. 2008; 3(1/2): 62-79.

[12] Bensouilah H, Aouici H, Meddour I, Yallese MA, Mabrouki T, Girardin F. Performance of coated and uncoated mixed ceramic tools in hard turning process. Measurement. 2016; 82: 1-18.

[13] Aouici H, Yallese MA, Chaoui K, Mabrouki T, Rigal J-F. Analysis of surface roughness and cutting force components in hard turning with CBN tool: Prediction model and cutting conditions optimization. Measurement. 2012; 45: 344-353.

[14] Hosseinia SB, Benob T, Klementa U, Kaminskia J, Ryttberg K. Cutting temperatures during hard turning-Measurements and effects on white layer formation in AISI 52100. Journal of Materials Processing Technology. 2014; 214 : 1293-1300.

[15] Oliveira AJ, Diniz AE, Ursolino DJ. Hard turning in continuous and interrupted cut with PCBN and whisker-reinforced cutting tools. Journal of Materials Processing Technology. 2009; 209: 5262-5270.

[16] Kurt A, Seker U. The effect of chamfer angle of polycrystalline cubic boron nitride cutting tool on the cutting forces and the tool stresses in finishing hard turning of AISI 52100 steel. Materials and Design. 2006; 26: 351-356.

[17] Dosbaeva GK, El Hakimb MA, Shalaby MA, Krzanowski JE, Veldhuis SC. Cutting temperature effect on PCBN and CVD coated carbide tools in hard turning of D2 tool steel. International Journal of Refractory Metals and Hard Materials. 2015; 50: 1-8.

[18] Paiva AP, Campos PH, Ferreira JR, Lopes LGD, Paiva EJ, Balestrassi PP. A multivariate robust parameter design approach for optimization of AISI 52100 hardened steel turning with wiper mixed ceramic tool. International Journal of Refractory Metals and Hard Materials. 2012; 30: 152-163.

[19] Raghavana S, Melkotea S, Hashimoto F. Laser tempering based turning process for efficient machining of hardened AISI 52100 steel. Journal of Manufacturing Processes. 2013; 15: 318-328.

[20] Sahoo AK, Sahoo B. Performance studies of multilayer hard surface coatings (TiN/TiCN/ $\mathrm{Al}_{2} \mathrm{O}_{3} / \mathrm{TiN}$ ) of indexable carbide inserts in hard machining: Part-I (An experimental approach). Measurement. 2013; 46: 2854-2867.

[21] Zuperl U, Cus F. Optimisation of cutting conditions during cutting by using neural networks. Robotics and Computer Integrated Manufacturing. 2003; 19: 189-199.

[22] Chinchanikar S, Choudhury SK. Effect of work material hardness and cutting parameters on performance of coated carbide tool when turning hardened steel: An optimization approach. Measurement. 2013; 46: 1572-1584.

[23] Sahu SK, Mishra PC, Orra K, Sahoo AK. Performance assessment in hard turning of AISI 1015 steel under spray impingement cooling and dry environment. Proc IMechE Part B: J Engineering Manufacture. 2015; 229 (2): 251-265. 
[24] Davim JP, Gaitonde VN, Karnik SR.Investigations into the effect of cutting conditions on surface roughness in turning of free machining steel by ANN models. Journal of Materials Processing Technology. 2008; 205: 16-23.

[25] Najiha MS, Rahman MM, Kadirgama K. Experimental investigation and optimization of minimum quantity lubrication for machining of AA6061-T6. International Journal of Automotive and Mechanical Engineering. 2015; 11: 27222737.

[26] Kumar R, Sahoo AK, Mishra PC, Das RK. Comparative investigation towards machinability improvement in hard turning using coated and uncoated inserts: part I experimental investigation. Advances in Manufacturing. 2018; doi.org/10.1007/s40436-018-0215-z.

[27] Bensouilah Hamza, Aouici Hamdi, Meddour Ikhlas, Yallese MA, Mabrouki Tarek, Girardin François. Performance of coated and uncoated mixed ceramic tools inhard turning process. Measurement. 2016; 82: 1-18.

[28] Rashid WB, Goel Saurav, Davim JP, Joshi SN.Parametric design optimization of hard turning of AISI 4340 steel. International Journal of Advanced Manufacturing Technology. 2016; 82:451-462.

[29] Kumar R, Sahoo AK, Mishra PC, Das RK. Comparative investigation towards machinability improvement in hard turning using coated and uncoated inserts: part II modeling, multi-response optimization, tool life, and economic aspects. Advances in Manufacturing. 2018; doi:10.1007/s40436-018-0214-0.

[30] Bensouilah Hamza, Aouici Hamdi, Meddour Ikhlas, Yallese MA. Performance of coated and uncoated mixed ceramic tools in hard turning process. Measurement. 2016. 82: 1-18.

[31] Kumar Ramanuj, Sahoo AK, Mishra PC, Das RK. Experimental investigation on hard turning using mixed ceramic insert under accelerated cooling environment International Journal of Industrial Engineering Computations 2018; 9: doi: 10.5267/j.ijiec.2017.11.002.

[32] Mhamdi MB, Salem SB, Boujelbene M, Bayraktar E. Experimental study of the chip morphology in turning hardened AISI D2 steel. Journal of Mechanical Science and Technology. 2013; 27 (11): 3451-3461.

[33] Anitha J, Das R, Pradhan MK. Multi-objective optimization of electrical discharge machining processes using artificial neural network. Jordan Journal of Mechanical and Industrial Engineering. 2016; 10 (1): 11-18.

[34] Karayel D. Prediction and control of surface roughness in CNC lathe using artificial neural network. Journal of Materials Processing Technology. 2009; 209: 31253137.

[35] Kumar R, Sahoo AK, Das RK, Panda A, Mishra PC. Modelling of flank wear, surface roughness and cutting temperature in sustainable hard turning of AISI D2 steel. Procedia Manufacturing. 2018; 20: 406-413.

[36] Sahoo SS, Rout AK. Prediction of erosion wear of granite-filled jute-epoxy composites using an artificial neural network. Composites: Mechanics, Computations, Applications. An International Journal. 2015; 6 (3): 193-205.

[37] Lin CL. Use of the Taguchi Method and Grey Relational Analysis to Optimize Turning Operations with Multiple Performance Characteristics. Materials and Manufacturing Processes. 2004; 19 (2): 209-220.

[38] Pal S, Malviya SK, Pal SK, Samantaray AK. Optimization of quality characteristics parameters in a pulsed metal inert gas welding process using grey- 
based Taguchi method. International Journal of Advanced Manufacturing Technology. 2009; 44: 1250-1260.

[39] Datta S, Bandyopadhyay A, Pal PK. Modeling and optimization of features of bead geometry including percentage dilution in submerged arc welding using mixture of fresh flux and fused slag. International Journal of Advanced Manufacturing Technology. 2008; 36: 1080-1090.

[40] Rout A, Satapathy A, Mantry S, Sahoo A, Mohanty T. Erosion wear performance analysis of polyester-GF-Granite hybrid composites using the Taguchi method. Procedia Engineering. 2012; 38: 1863-1882. 